\title{
Spatial variation in growth, maturation schedules and reproductive investment of female sole Solea solea in the Northeast Atlantic
}

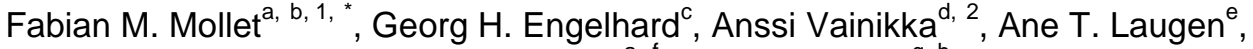 \\ Adriaan D. Rijnsdorp ${ }^{a, f}$, Bruno Ernande ${ }^{g, h}$
}

\author{
${ }^{a}$ Wageningen Institute for Marine Resources and Ecosystem Studies (IMARES), P.O. Box 68, 1970 AB IJmuiden, \\ The Netherlands \\ ${ }^{b}$ Evolution and Ecology Program, International Institute for Applied Systems Analysis, Schlossplatz 1, A-2361 \\ Laxenburg, Austria \\ ${ }^{c}$ Centre for Environment, Fisheries and Aquaculture Science (Cefas), Pakefield Road, Lowestoft NR33 OHT, UK \\ ${ }^{d}$ Institute of Coastal Research, Swedish Board of Fisheries, Öregrund, Sweden \\ e Swedish University of Agricultural Sciences, Department of Ecology, Box 7044, 75007 Uppsala, Sweden \\ $f$ Aquaculture and Fisheries group, Wageningen University, P.O. Box 338, $6700 \mathrm{AH}$, Wageningen, The \\ Netherlands \\ ${ }^{g}$ IFREMER, HMMN, Laboratoire Ressources Halieutiques, F-62200 Boulogne-sur-Mer, France \\ ${ }^{\mathrm{h}}$ Univ Lille Nord de France, F-59000 Lille, France \\ ${ }_{1}^{1}$ Present address : Blueyou Consulting Ltd, Zentralstrasse 156, 8003 Zürich, Switzerland \\ 2 Present address : Department of Biology, University of Eastern Finland (P.O. Box 111, FI-80101 Joensuu, \\ Finland).
}

*: Corresponding author : Fabian M. Mollet, email address : fabian.mollet@blueyou.com

\begin{abstract}
:
Latitudinal variation in life-history traits is often explained by phenotypically plastic responses or local adaptations to different thermal regimes. We compared growth, maturation schedules and reproductive investment of female sole Solea solea between 8 populations, covering much of the species' distribution in northern Europe, with respect to thermal gradients. An energy allocation model was fitted to size-age data, and probabilistic maturation reaction norms were estimated from size-age-maturity data. We found that northern populations from colder environments had higher rates of energy acquisition and reproductive investment, an intrinsic tendency to mature earlier, and had smaller asymptotic sizes than southern populations from warmer environments. Consequently, growth rate was higher before maturation but lower after maturation in the north compared to the south. This is opposite to Bergmann's rule according to which slower growth, delayed maturation and larger asymptotic sizes are usually observed at lower temperatures. The observed patterns could indicate strong countergradient thermal adaptation for rapid growth and development as well as sustained fecundity in the north, or indicate a response to other selection pressures correlated with the thermal gradient. Potentially higher mortality in northern populations during cold winters might be one of the key drivers of the observed geographical variation in growth and maturation of sole.
\end{abstract}

\section{Highlights}

Fishery data from three renown research institutions have been combined. A novel methodology is used to simultaneously estimate multiple life history traits. Plasticity and local adaptation are evaluated as response to the temperature gradient. Findings are opposite to Bergmann's rule indicating countergradient variation. Differences in natural mortality seems the main cause for life history adaptation.

Keywords: Countergradient variation ; Phenotypic plasticity ; Growth ; Maturation reaction norm ; Temperature ; Mortality-induced evolution 


\section{Introduction}

\section{Adaptation along thermal gradients}

52 The ecological and evolutionary processes behind latitudinal variation in phenotypes have 53 captured the attention of biologists for a long time, but in many cases the relative importance 54 of these processes remains unclear. With increasing human interference on ecosystems and 55 corresponding demands for assessment and mitigation of its consequences, it is urgent to 56 estimate the causes and magnitude of naturally occurring as well as human-induced processes 57 together with their interactions (Conover and Schultz, 1995, Conover et al., 2009).

58 Environmental heterogeneity in biotic or abiotic factors often changes gradually with latitude, 59 and one of the most studied drivers of latitudinal clinal variation is temperature. Several 60 biogeographical rules have been put forth to explain temperature-driven phenotypic patterns, 61 one example being Bergmann's rule (Bergmann, 1847). This rule, originally applied to 62 endotherms and mostly observed in birds and mammals (Blackburn and Hawkins, 2004), asserts that body size within species increases with latitude and colder climate, or that within closely related species differing mainly in relation to size, one would expect the larger species to be found at the higher latitude. This pattern may be explained by the lower surface to volume ratio of the larger body size if the dissipation of thermal energy is costly (colder 71 Bergmann's rule (Angilletta et al., 2004; Mousseau, 1997; Litzgus et al., 2004; Blanckenhorn and Demont, 2004; Conover et al., 2009). 
73 One key question in studies of latitudinal clines is to assess if the observed phenotypic

74 variation results from phenotypic plasticity, local adaptation or both (Arendt, 1997; Conover 75 et al., 2009; Partridge and Coyne, 1997; Van Voorhies, 1997). Experimental assessments of 76 phenotypic plasticity generally show that lower temperatures reduce developmental rates

more than growth rates resulting in larger sizes at a given developmental stage such as metamorphosis or maturation (Angilletta, 2008). This causality corresponds to Bergmann's rule and may be referred to as the temperature-size rule. This plastic response may have a genetic basis (coined as genotype by environment interaction; Lynch and Walsh 1998), and it often varies between populations of the same species (Laugen et al., 2003, 2005). A phenotypic pattern corresponding to the plastic response of a trait to differences in temperature along the spatial gradient is expected if there is no genetic variation along this gradient in this trait (hypothesis H1, Fig. 1A).

Besides phenotypic plasticity, two different patterns of genetic variation due to local adaptation can also affect latitudinal phenotypic clines (Fig 1; Conover and Schultz, 1995; Conover et al., 2009). Cogradient variation (CoGV; hypothesis H2, Fig. 1B) is expected if adaptive genetic variation is in the same direction as plastic variation along the gradient. Since genetic and plastic variation cumulate in the phenotypic response, the pattern of the temperature effect on a trait along the gradient is then reinforced (Trussell, 2000; Conover et al., 2009). The other pattern, countergradient variation (CnGV; hypothesis H3, Fig 1C), is expected if the direction of environmentally induced plastic variation is maladaptive in the sense that it is opposite to the expected adaptive response along the gradient. This may occur for instance in case of passive plastic responses arising from pure physical laws (e.g. warmer temperatures increase chemical reaction rates). This implies that adaptive genetic variation opposes plastic variation (Trussell, 2002; Skelly, 2004; Schultz et al., 1996; Marcil et al., 
97 2006; Conover et al., 2009; Conover and Present, 1990; Blanckenhorn and Demont, 2004).

98 CnGV dampens the effect of plasticity in phenotypic variation, and typically results in a flat 99 phenotypic pattern (Fig. 1C) that thus conceals substantial amounts of genetic variation 100 among populations (see e.g. Laugen et al., 2003). CnGV in growth has been detected mostly 101 in fishes, amphibians and insects (Conover et al., 2009; Conover and Present, 1990; Marcil et 102 al., 2006; Lonsdale and Levinton, 2011; Lindgren and Laurila, 2010; Schultz et al., 1996).

103 Both $\mathrm{CoGV}$ and $\mathrm{CnGV}$ can be detected by common garden experiments in which the 104 expression of traits is compared between individuals from different origin (Blanckenhorn and 105 Demont, 2004; Arnett et al., 1999; Conover and Present, 1990; Laugen et al., 2003; Lindgren 106 and Laurila, 2005; Marcil et al., 2006; Schultz et al., 1996). Reaction norm-based statistical 107 approaches, which are able to approximate the genotypic value of traits by combining 108 phenotypic and environmental field data (see e.g. Heino et al., 2002), could also be used for 109 detecting CoGV and CnGV. Here we combine energy allocation modelling together with a 110 reaction norm-based analysis of maturation to study phenotypic latitudinal clines in life111 history traits (energy acquisition, growth rate, reproductive investment, age and size at 112 maturation) and, to our knowledge, are the first ones to apply such an approach.

\section{Life history and energy allocation}

114 Life history traits are correlated both genetically and phenotypically, which is challenging for 115 studying life-history adaptation. Phenotypic variation across environments, be it from genetic and/or plastic origin, in the allocation of resources to growth and reproduction may maximize individuals' fitness in the environment they experience (Stearns, 1992; Roff, 1992). Since some energy is channelled towards reproduction after maturation, less energy becomes available to growth. Growth rate is thus expected to decrease discontinuously at maturation (West et al., 2001). Through modelling of energy allocation, the shape of an individual's 
121 growth curve therefore informs about the onset of maturation and reproductive investment

122 (Mollet et al., 2010; Brunel et al., in press).

123 The likelihood of maturation across different environments is conveniently illustrated by the 124 probabilistic maturation reaction norm (PMRNs, Heino et al., 2002). Reaction norms in 125 general describe how a certain genotype is translated into different phenotypes depending on 126 environmental conditions. PMRNs in particular depict how individuals' maturation 127 probability varies with age and size conditional on individuals being still immature and 128 having survived and grown until these age and size. The most important determinant for 129 maturation is likely growth rate (Bernardo, 1993), and PMRNs disentangle plastic variation 130 in maturation probability under the assumption that environmental variability affects 131 maturation through its effect on growth rate. Energy-allocation modelling and PMRNs are 132 therefore both powerful tools to assess life-history traits by simultaneously capturing the 133 inherent correlations among these traits and disentangling plastic and genetic variation. Their 134 application requires age, size and maturity data (and may be extended to incorporate any 135 other environmental or environmentally driven variables).

136 Sole

137 Here we study geographic patterns of variation in growth, maturation schedules and 138 reproductive investment of the common sole (Solea solea). This is an important commercial 139 species in waters down to about $60 \mathrm{~m}$ and targeted in demersal mixed fisheries (Millner et al., 140 2005). Its distribution ranges from the Mediterranean and north-west coast of Africa in the 141 south to the Irish Sea and the southern coast of Norway and the Kattegat in the north. Genetic 142 differentiation has been shown among Atlantic populations and between the Atlantic and the 143 Mediterranean (Exadactylos et al., 2003; Cuveliers et al., 2012). Synchronous variations in 144 recruitment, however, occur at a much smaller spatial scale and support the interpretation that 
145 ICES management areas (ICES, 2010) represent distinct biological stocks, although within

146 the North Sea for instance there are more sub-stocks present (Fig. 2, Rijnsdorp et al., 1992).

147 Growth rates in the Atlantic Ocean are higher than in the North Sea and the Mediterranean 148 (Deniel, 1981; Horwood, 1993). There are also clear geographical patterns of variation in the 149 fecundity-size relationship, egg size and timing of the spawning period (Witthames et al., 150 1995; Rijnsdorp and Vingerhoed, 1994; Fincham et al., 2013). These patterns may be related 151 to a gradient in fecundity-regulating mechanisms changing from determinate fecundity type 152 in the early spawning southern populations to indeterminate fecundity type in the later 153 spawning northern populations (Rijnsdorp and Witthames, 2005).

\section{Contribution of this study}

155 In this paper we take a novel approach to latitudinal life-history clines by using an energy 156 allocation model together with PMRNs to analyze how growth, maturation and reproductive 157 effort in female sole vary along a latitudinal gradient in relation to temperature as an 158 environmental factor of primary importance. From the observed population differences in 159 growth, maturity and reproduction we evaluate if these differences are due to $\left(\mathrm{H}_{1}\right)$ a plastic 160 response to temperature or $\left(\mathrm{H}_{2}\right)$ local adaptation generating $\mathrm{CoGV}$, consistent with 161 Bergmann's rule (Atkinson and Sibly, 1997), with warmer temperatures inducing faster 162 growth, earlier maturation and smaller asymptotic sizes, or $\left(\mathrm{H}_{3}\right)$ local adaptation creating $163 \mathrm{CnGV}$, i.e. genetic variation opposite to the plastic response. 


\section{Data sources and populations}

167 The data cover biological samples from eight populations distributed between the Bay of 168 Biscay in the south and the Irish Sea and North Sea in the north (Fig. 2). A total of 56380 169 females were sampled from scientific survey catches and commercial landings according to a 170 length-stratified design during the period 2000-2005 (Table 1). Three research institutes contributed to the data set: Cefas (England) covering the North Sea (management area IVb east, IVb west, and IVc ), the Irish Sea (management area VIIa), the Channel (management areas VIId and VIIe) and the Celtic Sea (IVfg); IFREMER (France) covering the Channel (management area VIId and VIIe) and the Bay of Biscay (management area VIIIa); and IMARES (The Netherlands) covering the North Sea (management area IVc, IVb west, IVb east).

For each female the following data were available: sampling date (day, month, year), age (years; determined by otolith reading assuming the $1^{\text {st }}$ of January as birth day), length $(\mathrm{cm})$, weight (g) and, for a subset of 15266 females, maturity stage (Mollet et al., 2007). Maturity 180 stage was determined by visual inspection of the gonads. Although detailed maturity staging 181 was not standardized among the three institutes, the distinction between immature and mature 182 females was carried out in a comparable manner. Age was transformed to a continuous 183 variable by accounting for the moment of sampling within a year. Since there is variation in 184 the onset of spawning among stocks, continuous age was additionally corrected for the 185 reported peak of spawning of each stock (Arbault et al., 1986; Fox et al., 2000; Rijnsdorp and 186 Vingerhoed, 1994).

187 No comparable measures of bottom temperature were available for all areas. Therefore, we 
188 used bottom temperatures from the bio-physical models NORWECOM (Søiland and Skogen,

189 2000) for areas north of $48^{\circ} \mathrm{N}$ and MARS3D (Huret et al., 2013) for area VIIIa. The mean 190 bottom temperature was estimated for each management area for the depth zone 10-50 m for 191 the period 1985-2008 and taking account of the surface of each depth layer. These weighted 192 means were then averaged by month over the period 1985-2008 to obtain relatively robust 193 monthly temperature indices per area $\bar{T}_{m, z}$ ( $m$ month, $z$ area; see Fig. 3).

\section{Growth and energy allocation}

\section{$195 \quad$ Energy-allocation based growth model}

196 Growth and underlying bioenergetics are studied using an energy allocation model, in which 197 the change $\partial w / \partial t$ in somatic weight $w$ according to time $t$, i.e. age, is given by the 198 difference between energy acquisition and energy expenditure :

$199 \quad \frac{\partial w}{\partial t}=a w^{\alpha}-c w$

200 where $a w^{\alpha}$ is the rate of net energy acquisition that scales with somatic weight to the power 201 of $\alpha$ with size-specific rate $a$ and $c w$ is the rate of reproductive investment scaling with somatic weight to the power of 1 with size-specific rate $c$. We assume $\alpha=0.75$ which seems a good approximation in general (West et al., 2001) and in flatfish in particular (Fonds et al., 1992; Mollet et al., 2010). Juveniles do not expend energy for reproduction and hence $c=0$, whereas after the onset of maturation at age $t_{\text {mat }}$ acquired energy is shared between growth and reproduction, so that $c>0$. In this model, energy expenditure for maintenance is accounted for by the size-specific acquisition rate, i.e. $a$ is the size-specific rate of energy 208 inflow that remains after first meeting the energy requirements for maintenance. This implies 209 that the rate of absolute energy acquisition and the rate of expenditure for maintenance scale 
210 equally with body weight (see e.g. Lester et al., 2004). Variation in size-specific net energy

211 acquisition rate $a$ thus results from a combination of variation in size-specific absolute 212 energy acquisition rate and size-specific maintenance rate. These considerations are 213 important for interpretation because differences in $a$ across stocks may not only result from 214 differences in size-specific absolute energy acquisition rate but also in size-specific 215 maintenance rate.

216 By integration of eq. (1), juvenile $(c=0)$ and adult $(c>0)$ growth curves describing somatic 217 weight as a function of age are obtained. An individual starts to grow following juvenile 218 growth until it matures and switches to the adult curve because of energy expenses for 219 reproduction. A single lifetime growth curve is obtained by combining juvenile and adult 220 growth functions using the Heaviside step function, $H_{t_{\mathrm{mat}}}(t)\left(H_{t_{\mathrm{mat}}}(t)=0\right.$ for $t<t_{\mathrm{mat}}$ and $221 H_{t_{\text {mat }}}(t)=1$ for $\left.t \geq t_{\text {mat }}\right)$, to describe the switch between one curve to another occurring at 222 the onset of maturation $t_{\text {mat }}$ corresponding to the size at maturation $w_{\text {mat }}$ :

$$
w^{1-\alpha}(t)=\left(1-H_{t_{\mathrm{mat}}}(t)\right)\left[w_{0}^{1-\alpha}+a(1-\alpha) t\right]+H_{t_{\mathrm{mat}}}(t)\left[\frac{a}{c}-\left(\frac{a}{c}-w_{\mathrm{mat}}^{1-\alpha}\right) \mathrm{e}^{-c(1-\alpha)\left(t-t_{\mathrm{mat}}\right)}\right]
$$

224 with $w_{0}$ being the somatic weight at birth of an individual assumed to be constant across 225 populations at $2.5 \mathrm{mg}$ (Mollet et al., 2010).

226 The three energy allocation parameters $a, c$, and $w_{\text {mat }}$ were estimated by fitting equation 227 (2.1) to age-at-somatic weight data. Somatic weight of an individual varies seasonally in 228 relation to the energy reserves and gonad weight. To avoid the risk of confounding between 229 weights of different compartments due to variable body condition when using total weight, 230 length records were transformed to somatic weight by using a length-weight relationship (see 
231 eq. 6 below) evaluated at the seasonal minimal average body condition in each management

area.

233 The available weight-at-age data are biased and not representative of the population because 234 of (i) the length stratified sampling design and (ii) truncation of the size distribution due to 235 the mesh size used (research vessel survey samples) and the minimum landing size 236 (commercial samples). In contrast, sampling and fishing are not selective for age (conditional 237 on size), and we can therefore assume that our samples provide representative age 238 distributions within a size class. By fitting the growth model to age-at-somatic weight instead 239 of somatic weight-at-age data, the sampling bias described above can be avoided. Growth 240 function (2.1) was inverted to obtained age $t$ as a function of somatic weight $w$ using a size$241 S\left(w-w_{\text {mat }}\right)$ instead of an age-dependent Heaviside step function:

$\left.t(w)=\left(1-H_{w_{\mathrm{mat}}}(w)\right)\left[\frac{1}{a(1-\alpha)}\left(w^{1-\alpha}-w_{0}^{1-\alpha}\right)\right]+H_{w_{\mathrm{mat}}}(w) \mid t_{\mathrm{mat}}-\left(\frac{1}{c(1-\alpha)} \log \left(\frac{a / c-w^{1-\alpha}}{a / c-w_{\mathrm{mat}}^{1-\alpha}}\right)\right)\right\rfloor$

\section{Growth model fitting}

244 Nonlinear mixed effect modelling (NLME) was used to fit the inversed energy allocation 245 model (2.2) to age-at-somatic weight data. Following Pinheiro and Bates (2004), the NLME 246 model was formulated as

$247 \quad \ln \left(1+t_{i, w, z}\right)=\ln \left(1+t\left(w, \boldsymbol{\mu}_{z}\right)\right)+\varepsilon_{i, w, z}$

248 where $t_{i, w, z}$ is the age of individual $i$ having somatic weight $w$ in management area $z$, $249 t\left(w, \boldsymbol{\mu}_{z}\right)$ is the inverted growth model given in equation (2.2) with $\boldsymbol{\mu}_{z}=\left(a_{z}, c_{z}, w_{\text {mat }, z}\right)^{\mathrm{T}}$ the 250 vector of energy allocation parameters to be estimated for management area $z$ (with bold 251 denoting vectors or matrices and $\mathrm{T}$ transpose), and $\varepsilon_{i, w, z}$ is a normally distributed residual 
252 term. Data were $\ln +1$-transformed to achieve normality of the residuals and a residual

253 variance function with differing variances for each management area was included in the

254 model to account for heteroscedasticity of residuals across areas.

255 To evaluate variation in the three energy allocation parameters across management areas 256 areas and its potential relationship with latitude or temperature, the vector of parameters $\boldsymbol{\mu}_{z}$ 257 was described as the sum of a vector of fixed effects representing energy allocation 258 parameters as linear functions $\boldsymbol{\mu}\left(x_{z}\right)=\left(a_{0}+a_{1} x_{z}, c_{0}+c_{1} x_{z}, w_{\text {mat }, 0}+w_{\text {mat }, 1} x_{z}\right)^{\mathrm{T}}$ of the 259 relevant covariate $x_{z}$, i.e. either the average latitude $L a t_{z}$ or the average temperature $\bar{T}_{z}$ in 260 each management area, plus a vector of random effects $\Delta \boldsymbol{\mu}_{z}=\left(\Delta a_{z}, \Delta c_{z}, \Delta w_{\text {mat }, z}\right)^{\mathrm{T}}$ 261 corresponding to the deviation of parameters in management area $z$ relative to the prediction 262 of the fixed effect linear model. Parameters in each management area $z$ were thus estimated 263 as

$\boldsymbol{\mu}_{z}=\boldsymbol{\mu}\left(x_{z}\right)+\Delta \boldsymbol{\mu}_{z}=\left(a_{0}+a_{1} x_{z}+\Delta a_{z}, c_{0}+c_{1} x_{z}+\Delta c_{z}, w_{\mathrm{mat}, 0}+w_{\text {mat }, 1} x_{z}+\Delta w_{\mathrm{mat}, z}\right)^{\mathrm{T}}$

265 where $\Delta \boldsymbol{\mu}_{z}$ follows a multivariate normal distribution with mean vector $\mathbf{0}$ and a symmetric 266 covariance matrix $\Sigma^{2}\left(\Delta \boldsymbol{\mu}_{z} \sim \operatorname{MVN}\left(\mathbf{0}, \Sigma^{2}\right)\right.$ and $\boldsymbol{\mu}_{z} \sim \operatorname{MVN}\left(\bar{\mu}, \Sigma^{2}\right)$.

267 To estimate variation in energy allocation parameters across areas without any hypothesis 268 about its cause, we started by fitting a simple "area random effect model" by setting covariate $269 x_{z}$ to 0 , variation being then represented by the area random effects $\Delta \boldsymbol{\mu}_{z}$ only. The 270 estimation algorithm requires providing starting values for fixed effect parameters. Because 271 of potential divergence depending on initial values, the model was repeatedly fitted over a 272 grid of starting values and the solution with the highest maximum likelihood was selected. In 273 a second step, the effects of latitude and temperature on energy allocation parameters were 
274 tested by fitting successively a "latitude effect model" and a "temperature effect model" by

respectively setting $x_{z}$ to the average latitude and the average temperature in each management area. The latitude and temperature effect models were initially adjusted with a symmetric covariance matrix $\Sigma^{2}$ describing the random component of the model as in the area random effect model. As inclusion of covariates in the fixed component was supposed to account for at least part of the observed variation in energy allocation parameters across areas, the random component structure of the model was then simplified using maximum likelihood ratio tests between nested models obtained by either simplifying the covariance structure (e.g. from a symmetric to a diagonal matrix) or by removing random effects on some or all parameters (Pinheiro and Bates 2004). Once the random component structure was selected, the effects of covariates on the fixed component were tested by asymptotic t-tests (Pinheiro and Bates 2004). All latitude and temperature effect models were adjusted using the initial values selected when fitting the area random effect model to obtain comparable results. The relative merits of the three models (area random effect, latitude effect and temperature effect) were evaluated by comparing the final models after selection on the basis of the Akaike Information Criterion (AIC).

Beyond the three energy allocation parameters, additional parameters were indirectly estimated: the onset of maturation in area $z$ estimated as $t_{\mathrm{mat}, z}=t\left(w_{\mathrm{mat}}, \boldsymbol{\mu}_{z}\right)$, the asymptotic somatic weight obtained as $w_{\infty, z}=\left(a_{z} / c_{z}\right)^{1 /(1-\alpha)}$, and somatic weight at different ages $t$ calculated as $w_{t, z}=w\left(t, \boldsymbol{\mu}_{z}\right)^{1 /(1-\alpha)}$ according to equation (2.1). Standard errors of directly and indirectly estimated parameters were estimated by bootstrapping with 500 repetitions. NLME models were fitted using the nlme package (Pinheiro et al., 2011) of the statistical software R (R Development Core Team 2011). 
298 Because individuals have different schedules for the start of vitellogenesis and because spent 299 and immature ovaries are sometimes difficult to distinguish it was recommended to study the 300 maturation characteristics prior to spawning as soon as the probability to detect maturity (or 301 as vitellogenesis had started) is high (Mollet et al., 2007). As the spawning seasons differ 302 between populations (Fig. 7 , Rijnsdorp and Vingerhoed, 1994), we determined specific 303 sampling periods for each population based on the seasonal cycle in body condition. It is well 304 established that the seasonal cycle in body condition reflects the seasonal pattern in feeding 305 and spawning. Body condition is built up during the feeding period, while a minimum 306 condition occurs immediately after fish have reproduced (Rijnsdorp, 1990; Deniel, 1981). 307 Body condition was modelled according to the following seasonal weight-length-relationship:

$308 \ln \left(w_{l, m}\right)=\beta_{0}+\beta_{1} m+\beta_{2} m^{2}+\beta_{3} m^{3}+\beta_{l} \ln (l)+\varepsilon_{l, m}$

309 where $w_{l, m}$ is gutted weight (including gonads), $l$ is length $(\mathrm{cm}), m$ is month in the year, $310 \varepsilon_{l, m}$ is a normally distributed residual term, and the $\beta$ 's are the parameters of the model.

311 The duration of spawning was approximated by the difference between the estimates for peak 312 spawning taken from literature (Arbault et al., 1986; Fox et al., 2000; Rijnsdorp and 313 Vingerhoed, 1994) and the spawning low or end of spawning derived from the minimal 314 annual condition (see eq. 5 above, Fig. 3). To analyze maturation, we selected data from the 5 315 months prior to the expected spawning peak of the corresponding stocks. Model (5) was also 316 used to estimate somatic weight used for fitting the inverted growth model (2.2) (see Section 317 "Growth and energy allocation model" above).

318 Maturity ogives according to age (i.e., maturity probability-at-age ; see Table 1) are biased 
because they do not account for growth plasticity and survival probability. To account for this, probabilistic maturation reaction norms (PMRNs) were used to describe the probability

327 where $o_{t, l}$ is the proportion of mature fish per age and length class, $t$ is continuous corrected 328 age $(\mathrm{yr}), l$ is length $(\mathrm{cm})$, and the $\beta$ 's are the parameters of the model. As first time

$$
p(t, l)=\frac{o(t, l)-o(t-1, l-\Delta l)}{1-o(t-1, l-\Delta l)}
$$

336 We assumed that the growth rate and mortality rate at a certain age and size are the same for 337 immature and mature individuals. Although this may not be true in reality, the method is 338 robust to the relaxation of this assumption (Barot et al., 2004). $L_{\mathrm{P} 50}(t)$ is used to denote the 339 length at a given age $t$ at which the probability of becoming mature is $50 \%$. Estimation of 340 length increments was based on the fitted growth curves previously estimated (eq. 2 , see 
341 above). To obtain confidence intervals of the $L_{\mathrm{P} 50}$ values, the original data set was

342 bootstrapped for each area with $10^{4}$ repetitions.

Differences in PMRN between the areas, i.e. in $L_{\mathrm{P} 50}$-at-age, were tested using a randomization approach. For this purpose, each data point was randomly allocated to a management area irrespective of its geographical origin while respecting the same sample sizes per area as in the original dataset, thus randomizing data across management areas. From this randomized data set, PMRNs in each area and differences in $L_{\mathrm{P} 50}$-at-age between areas were calculated. This procedure was repeated $10^{4}$ times. To assess how likely the observed differences between areas might have arisen only by chance, the p-value of the randomization test was given as the proportion of randomized samples for which the differences in $L_{\mathrm{P} 50}$-at-age were equal to or greater than the observed differences.

352 Finally, the respective effects of latitude and temperature on the onset of maturation were tested by regressing $L_{\mathrm{P} 50}(t)$ against the average latitude and the average temperature in each management area. Regressions were weighted by the inverse of the bootstrapped variances to give more weight to better estimated $L_{\mathrm{P} 50}(t)$.

\section{Results}

357 The average bottom temperature decreased with latitude (Pearson's correlation, $r_{p}=-0.95, p$ $358<0.0005)$, whereas the amplitude between minimal and maximal annual temperature 359 increased $\left(r_{p}=0.71, p=0.047\right.$; Fig. 3). The populations at lower latitudes living in warmer 360 conditions started spawning earlier than stocks at higher latitudes $\left(r_{p}=0.93, p<0.001\right)$, and 361 also spawned for longer periods as was suggested by the approximated end of spawning (date 362 of minimal condition) $\left(r_{p}=-0.81, p=0.014\right.$; Fig. 3). Earlier spawning correlated with higher 
363 average temperature $\left(\mathrm{r}_{\mathrm{p}}=-0.91, \mathrm{p}=0.001\right)$ and longer spawning duration correlated with 364 smaller intra-annual variation in temperature $\left(r_{p}=0.75, p=0.030\right)$.

365 The three growth models (the area random effect model, the latitude effect model and the 366 temperature effect model) fitted very well age-at-size data (see Fig. 4 with the temperature 367 effect model as an example). The area random effect model detected significant variation in 368 energy acquisition rate $a$, reproductive investment rate $c$, and size at maturation $w_{\text {mat }}$ across 369 sole populations (Likelihood Ratio Tests (LRT) between complete model and model 370 excluding random effect on $a: \chi_{3}^{2}=94.03, \mathrm{p}<0.001 ; c: \chi_{3}^{2}=95.39, \mathrm{p}<0.001 ;$ and $w_{\text {mat }}$ : $371 \chi_{3}^{2}=151.66, \mathrm{p}<0.001$; see population-specific values of $\boldsymbol{\mu}_{z}=\overline{\boldsymbol{\mu}}+\Delta \boldsymbol{\mu}_{z}$ in Table 2). The 372 latitude and the temperature effect models that included a linear dependency (eq. 4) of growth 373 parameters (eq. 2.2) on latitude or temperature resulted in a better (lower) AIC than the 374 model area random effect (Table 3), with a clear advantage for the temperature effect model 375 over the latitude effect model. The linear latitude or temperature effects were significant for 376 all parameters (Table 4) and explained varying parts of the variation detected across areas 377 depending on the parameter considered. Variance in reproductive investment $c$ and related 378 co-variances with the other parameters was not significant (LRT: $\chi_{3}^{2}=4.23, p=0.238$ and $379 \chi_{3}^{2}=2.41, \mathrm{p}=0.491$ for the latitude and temperature model, respectively); variance in energy 380 acquisition rate $a$ was significant (LRT: $\chi_{2}^{2}=807.18, \mathrm{p}<0.001$ and $\chi_{2}^{2}=764.44, \mathrm{p}<0.001$, 381 respectively) but decreased by $92.5 \%$ and $91.5 \%$ respectively; and variation in size at 382 maturation $w_{\text {mat }}$ was significant (LRT: $\chi_{2}^{2}=978.04, \mathrm{p}<0.001$ and $\chi_{2}^{2}=849.39, \mathrm{p}<0.001$, 383 respectively) and decreased by $1.5 \%$ and $18 \%$ respectively. Moreover, for the temperature 384 effect model, the covariance matrix of random effects $\Sigma^{2}$ could be simplified to a diagonal 
385 matrix indicating that a linear temperature effect explained most of co-variation between

386 energy acquisition and size at maturation across areas (LRT between model with and without

387 covariance: $\left.\chi_{1}^{2}=0.00, \mathrm{p}=1\right)$. Since the temperature effect model had the highest likelihood 388 and the lowest AIC, the following results mainly focus on the temperature effect model (see 389 eq. 5).

390 The size-specific life-history estimates showed a clear spatial pattern: rates of energy 391 acquisition $a$ and reproductive investment $c$ decreased with increasing temperature 392 (increased with increasing latitude), whereas the onset of maturation (size $w_{\text {mat }}$ or age $t_{\text {mat }}$ at 393 maturation) was delayed at warmer temperature (precocious at higher latitude, Fig. 5). 394 Temperature increase led to a greater proportional decrease in energy acquisition $a$ than in 395 reproductive investment $c$, as measured by the ratios between their respective slopes and 396 intercepts (Table 4). As a result the asymptotic weight $w_{\infty}=(a / c)^{4}$ increased with increasing 397 temperature (and decreased with increasing latitude, Fig. 6, Table 2).

398 In summary, sole at lower temperatures in the north grew faster, matured earlier, invested 399 more into reproduction, and reached a smaller asymptotic size. As a consequence growth 400 curves differed across populations between juvenile and adult stages: juvenile size-at-age was 401 larger at lower temperatures in the north whereas adult size-at-age was larger at higher 402 temperatures in the south (Fig. 4 and 6). Since the majority of sole have matured by age 3 in 403 all but one of the populations (see maturity probability-at-age in Table 1 and $t_{\text {mat }}$ in Table 2), 404 the trend in size-at-age with temperature already started to reverse at age 3 (Fig. 6).

405 The eight sole populations showed variable probabilistic maturation reaction norm (PMRN) 406 shapes, with PMRN midpoints (or $L_{\mathrm{P} 50}$ ) that either decreased with age (such as in area $8 \mathrm{a}$ ) or 
407 slightly increased with age (such as in area 7 fg, Fig. 7). As a result, the relationships of $L_{\mathrm{P} 50}$ 408 with temperature or latitude depended on the age group considered. For age groups 2 to 4 409 across which about $90 \%$ of individuals mature, $L_{\mathrm{P} 50}$ tended to increase with increasing 410 temperature (decrease with increasing latitude, Fig. 8). For age 3 when most individuals 411 spawn for the first time, the regression on temperature was significant at a level of $\alpha=0.103$, 412 for latitude at a level of $\alpha=0.025$. The maturation probability at a certain size and age was 413 thus higher in the north than in the south, implying that maturation occurs on average earlier 414 in the north, where temperatures are lower, than in the south, where temperatures are higher. 415 Randomization tests $\left(10^{4}\right.$ replicates $)$ performed for age 3 showed that most of the pairwise 416 differences in $L_{\mathrm{P} 50}$ between areas were significant except for the following groups of 417 populations: 1) 7a, 7e \& 4c; 2) 7a \& 4bE; 3) 4bW \& 7d (Table 5).

\section{Discussion}

\section{Main findings}

420 We examined a set of biological traits in eight sole populations experiencing different 421 temperature conditions along a latitudinal gradient. Comparison of energy allocation models 422 fitted to different populations revealed that northern, cold-water populations were 423 characterized by faster energy acquisition rates, earlier onset of maturation at smaller sizes, 424 higher reproductive investment, and lower asymptotic weights. PMRNs - which, by 425 controlling for differences in growth rate, can be interpreted as an approximation of the 426 genotypic value of maturation probability under the assumption that most plastic variation in 427 maturation age and size originates from variation in growth - furthermore revealed that at a 428 given age and size, fish of northerly populations were more likely to commence reproduction 
than fish in southerly populations (i.e. had lower reaction norm midpoints or $L_{\mathrm{P} 50}$ values).

430 Can the observed differences be attributed to phenotypic plasticity or are populations locally 431 adapted to their specific environmental conditions?

\section{$432 \quad$ Plasticity vs. local adaptation to temperature}

433 The observed pattern is in line with Converse Bergmann's rule, according to which 434 individuals in the north grow to smaller asymptotic size, and contrasts experimental results 435 showing that phenotypic plasticity accelerates growth rates and maturation in warmer 436 environments (Angilletta, 2008). Under hypothesis $\mathrm{H}_{1}$ assuming phenotypic plasticity in 437 response to temperature as bare cause of variation, cold conditions are expected to lead to 438 slow energy acquisition rate and thus reduced immature growth rate (e.g. Toresen, 1990; 439 Grift et al., 2003; Abookire and Macewicz, 2003; Brander, 2007, Fig. 1A), later onset of 440 maturation (e.g. Jørgensen, 1990; O’Brien, 1999; Engelhard and Heino, 2004), lower 441 reproductive investment, and higher asymptotic weight (Rijnsdorp, 1990; Roff, 1992; 442 Abookire and Macewicz, 2003; Brunel and Dickey-Collas, 2010). No change in the PMRN 443 would be expected since the PMRN concept assumes that environmental variation only 444 directly impacts growth rates (Heino et al., 2002; see also Vainikka et al., 2009). The patterns 445 observed here are thus opposite to those expected from phenotypic plasticity. Since CoGV as 446 assumed in hypothesis $\mathrm{H}_{2}$ would reveal the same life-history pattern along the gradient as the 447 bare effect of plasticity (Fig. 1B), it can be excluded likewise that the studied sole 448 populations were subject to CoGV.

449 In contrast, the observed patterns might be in line with hypothesis $\mathrm{H}_{3}$ assuming local 450 adaptation generating countergradient genetic variation (CnGV), opposite to the 451 phenotypically plastic response (Fig. 1C). In case of $\mathrm{CnGV}$, it is usually observed that 
populations living in colder environments show similar energy acquisition rates compared to populations in warmer environments (Conover and Present, 1990). In theory, very strong CnGV in energy acquisition, and resulting growth rate, may overcompensate for the plastic decrease in energy acquisition at lower temperatures and lead to size patterns complying with Bergmann's rule, i.e. larger sizes at higher latitudes and colder environments (Conover et al. 2009). This is precisely what we observed for juvenile size-at-age. Local adaptation may also have occurred in maturation generating again $\mathrm{CnGV}$. PMRN midpoints increased with increasing temperature (decreased with increasing latitude) which can be interpreted as CnGV compensating for delayed maturation expected from the plastic decrease in growth rate in colder environments (see also Vainikka et al. 2009). Finally, the observed increase of reproductive investment with increasing latitude and decreasing temperature may also be interpreted as local adaptation that generates $\mathrm{CnGV}$ in the sense of mitigating the decrease in fecundity due to the plastic decrease of energy acquisition. It results that higher latitudes and colder environments were also characterized by earlier maturation and stronger reproductive investment so that resulting adult size-at-age and asymptotic size followed a converse Bergmann's rule contrary to juvenile size-at-age. This highlights the complexity of predicting the result of local adaptation on a single trait, here size-at-age, when multivariate evolution of life-history traits - growth rate, maturation, reproductive investment - is involved.

The pattern observed across the studied sole populations reveals that local adaptation not only compensates but clearly overrides the plastic response to temperature. We might therefore assume either that $\mathrm{CnGV}$ is highly adaptive or that life history is affected by other factors than temperature that correlate with the latitudinal gradient, as physiological adaption to temperature is unlikely to be the only factor generating differences in life history between populations. 


\section{Adaptation to other gradient-related factors} (Abrams and Rowe 1996).

As an alternative to highly adaptive $\mathrm{CnGV}$ in response to the temperature gradient, local adaptation along a gradient in natural mortality could be a plausible explanation. It is well known that both adults and juveniles of northern sole populations can suffer significantly elevated mortality rates during cold winters (Woodhead, 1964; Horwood and Millner, 1998). Environmentally induced mortality may increase variability in recruitment (Rijnsdorp et al., 1992), in line with the observed latitudinal trend in the coefficient of variation in recruitment from $19 \%$ in the Bay of Biscay to $90 \%$ in the North Sea (Table 2). Since size-independent mortality accelerates the pace of life history (Ernande et al., 2004; Jørgensen, 2013), it could be the main driver for the observed higher juvenile growth rates, earlier maturation and higher reproductive investment of northern populations. However, also negatively sizedependent mortality could induce higher juvenile growth rates but not earlier maturation

Differences in per capita food availability (including as a result of the effect of population density on growth) might also explain our results and would be reflected in the different estimates of the size-specific energy acquisition rate $a$. Since these estimates are higher for the northern populations, per capita food availability would have to be assumed higher in the north (Fig. 5). There is however no evidence for such pattern, as estimates for food availability are not available and exploitation rates, from which an effect of densitydependent growth could be inferred, have been similar across populations (see below).

The results of this study are thus in line with local adaptation either due to $\mathrm{CnGV}$ generated by physiological adaptation to temperature along the latitudinal gradient (CnGV; hypothesis $\mathrm{H} 3$ in Fig. 1C), or due to life-history adaptation to the latitudinal trend in natural mortality. This inference corroborates the results of population genetic studies using microsatellite 
500 markers that revealed isolation by distance. The genetic structure reveals at least three

different populations (Kattegat/Skagerrak region, the North Sea and the Bay of Biscay) and perhaps a fourth one in the Irish/Celtic Sea (Cuveliers et al., 2012). More recent ongoing studies using gene-linked SNP-markers suggest the presence of an even more fine-grained genetic structure, possibly due to local adaptations (G. Maes, pers. comm.).

505 Anthropogenic impacts?

506 There is evidence that exploited fish populations may adapt to human exploitation (Law and 507 Grey, 1989; Heino \& Godø, 2002; Jørgensen et al., 2007). As such, spatial differences in sole 508 life-history could arise if exploitation was strongly heterogeneous spatially. In North Sea 509 sole, females now mature at a younger age and smaller size than they did 4-5 decades ago, 510 consistent with fisheries-induced evolution (Mollet et al., 2007). Differences in exploitation 511 history therefore might have contributed to the presently observed differences in life-history 512 traits among populations. Historically, sole had been exploited relatively lightly. The 513 development of an intensive target fishery for sole began in the 1960s in the North Sea when 514 vessels started using beam trawls rigged with heavy chains to chase sole up from the sea bed 515 (Millner et al., 2005; Rijnsdorp et al., 2008). In the 1960s fishing mortality almost tripled 516 from around 0.2 in the late 1950 to a level of $0.5-0.6$ since 1970 . Since the $1980 \mathrm{~s}$ all 517 populations have been exploited at fishing mortality rates between 0.4 and 0.6 , except for $7 \mathrm{e}$ 518 which had a fishing mortality rate of around 0.3 (ICES, 2010; Table 2). Given the rate of 519 change in PMRN midpoints ascribed to fisheries-induced evolution $\left(0.1 \mathrm{~cm} . \mathrm{yr}^{-1}\right.$ : Mollet et al., 520 2007), the amplitude of variation in the PMRN midpoints observed over the latitudinal 521 gradient (about $5 \mathrm{~cm}$ : Fig. 8) could only arise from fisheries-induced evolution if exploitation 522 rates differed extremely strongly between populations. Since exploitation rates were roughly 523 similar across the latitudinal gradient, although they may have contributed to the observed 
524 pattern, it appears unlikely that they could have been the main cause of the observed

\section{Growth-independent temperature effect on PMRNs?}

PMRNs disentangle the effects of environmental factors like temperature that act on 528 maturation via variation in growth from the underlying (genetically determined) maturation 529 process (Heino et al., 2002). However, temperature might also have a direct growth530 independent effect on maturation probability: under warmer conditions, it has been reported 531 that fish of a given age and size are more likely to mature by accelerating developmental rates 532 (Kurita et al., 2003; Dhillon and Fox, 2004; Kuparinen et al., 2011, Neuheimer et al., 2012). 533 Such growth-independent temperature effect would lead to a downward shift of the PMRN 534 towards lower $L_{\mathrm{P} 50}$ values in warmer areas (Grift et al., 2003; Mollet 2007). However, the 535 differences in PMRNs found in this study were opposite to those expected from a growth536 independent temperature effect: the cold-water populations were more likely to mature at a 537 given age and size. Also condition and resource availability have been reported to explain 538 variation in maturation probability additional to growth rates in terms of age and length (Grift 539 et al., 2007, Uusi-Heikkilä et al., 2011). However, relating condition to maturation from wild 540 capture data is uncertain because condition changes seasonally as a consequence of the 541 annual process of reproduction: condition increases as an individual starts to store energy 542 resources in somatic tissue for the subsequent spawning season and decreases as these 543 resources are allocated to gonads that are subsequently spawned. Since maturity can be 544 observed only as soon as energy resources have been allocated to gonads, the condition of an 545 individual observed at this same moment is not a robust indicator for the likelihood of its 546 maturity. Furthermore, condition may randomly vary on short time scales due to short-term 547 changes in food availability (see discussion about per capita food availability above). If there 
548 were persistent longer-term differences in per capita food availability between the

549 populations it would likely also have induced a difference in average growth rates in terms of 550 length, which would however have been captured by the PMRN. But there is no evidence to 551 support any such speculations (see above). Given that the observed patterns were opposite to 552 those expected from the major potential environmental effect for which there is evidence for 553 differences between the environments of the here studied populations, i.e. temperature, we 554 conclude that the population differences in PMRNs found in this study are likely of genetic 555 nature.

\section{Conclusions}

557 We used a unique and novel approach to model growth and life history, which is more 558 informative than the commonly used Von Bertalanffy growth model and overcomes the usual 559 problems of biased sampling and size stratification in fisheries data. The approach has 560 therefore the potential to become a standard application in fisheries science. For a meaningful 561 analysis of this kind (also including the PMRN) an appropriate database of individual data is 562 however crucial (see Fig. 1), and by combining data from three research institutions this 563 paper represents a unique opportunity in this sense. Variation in life history between sole 564 populations in the North-East Atlantic is found to be opposite to Bergmann's rule and thus 565 neither the result of a phenotypically plastic response to temperature nor co-gradient adaptive 566 variation. The observed pattern is consistent with local adaptation leading to countergradient 567 variation. To our knowledge, this would be one of the first cases where CnGV is so strong 568 that it does more than compensates for the plastic effects resulting from the temperature 569 gradient, and thus leads to phenotypic variation opposite to the expectation from purely 570 plastic variation. We hypothesise that other factors than temperature that are correlated with 571 the latitudinal gradient must have played a role in overshooting the effect of CnGV. To our 
572 current knowledge, strong latitudinal differences in natural mortality rates between

populations offer the most plausible explanation for the life-history patterns observed in this study.

577 This research has been initially supported by the European Marie Curie Research Training 578 Network FishACE (Fisheries-induced Adaptive Changes in Exploited Stocks, contract 579 MRTN-CT-2004-005578) and was completed with support by the Specific Targeted 580 Research Project FinE (Fisheries-induced Evolution, contract SSP-2006-044276) under the 581 Scientific Support to Policies cross-cutting activities, both funded through the European 582 Community's Sixth Framework Programme. It does not necessarily reflect the views of the 583 European Commission and does not anticipate the Commission's future policy in this area. 584 Additionally, GHE was supported by the UK Department for the Environment, Food and 585 Rural Affairs (Defra) through projects MF1201 and MF1108 and ADR by the strategic 586 research programme "Sustainable spatial development of ecosystems, landscapes, seas and 587 regions" funded by the Dutch Ministry of Agriculture, Nature Conservation and Food 588 Quality. BE thanks Gérard Biais for providing data and expertise on sole in the Bay of 589 Biscay. 
Abookire, A.A., Macewicz, B.J. 2003. Latitudinal variation in reproductive biology and growth of female Dover sole (Microstomus pacificus) in the North Pacific, with emphasis on the Gulf of Alaska stock. Journal of Sea Research 50, 187-197.

Abrams, P.A., Rowe, L. 1996. The effects of predation on the age and size of maturity of prey. Evolution, 50, 1052-1061.

Angilletta, M.J. 2008. Thermal adaptation - a theoretical and empirical Synthesis. Oxford University Press.

Angilletta, M.J., Niewiarowski, P.H., Dunham, A.E., Leaché, A.D, Porter, W.P., 2004. Bergmann's clines in ectotherms: illustrating a life-history perspective with sceloporine lizards. American Naturalist 164, $168-183$.

Arbault, S., Camus, P., Lebec, C., 1986. Estimation of the common sole (Solea vulgaris Quensel 1806) spawning stock by egg survey in the Bay of Biscay. Journal of Applied Ichthyology 2, 145-156.

Arendt, J.D., 1997. Adaptive intrinsic growth rates: an integration across taxa. The Quarterly Review of Biology 72, 149-177.

Arnett, A.E., Gotelli, N.J., Url, S., 1999. Geographic variation in life-history traits of the ant lion, Myrmeleon immaculatus: evolutionary implications of Bergmann's Rule. Evolution 53, 1180-1188.

Atkinson, D., Sibly, R.M., 1997. Why are organisms usually bigger in colder environments? Making sense of a life history puzzle. Trends in Ecology and Evolution, 12, 235-239.

Barot, S., Heino, M., O’Brien, L., Dieckmann, U., 2004. Estimating reaction norms for age and size at maturation when age at first reproduction is unknown. Evolutionary Ecology Research 6, 659-678.

Bergmann, C., 1847. Über die Verhältnisse der Wärmeökonomie der Thiere zu ihrer Grösse. Göttinger Studien 3, 595-708.

Bernardo, J., 1993. Determinants of maturation in animals. Trends in Ecology and Evolution 8, 166-173.

Blackburn, T.M., Hawkins, B.A., 2004. Bergmann's rule and the mammal fauna of northern North America. Ecography 27, 715-724.

Blanckenhorn, W.U., Demont, M.D., 2004. Bergmann and converse Bergmann latitudinal clines in arthropods: two ends of a continuum? Integrative and Comparative Biology 44, 413-424. 
618 Brander, K.M., 2007. The role of growth changes in the decline and recovery of North Atlantic cod stocks since 1 619 4620 621 622 10 11 1970. ICES Journal of Marine Science 64, 211-217.

Brunel. T., Dickey-Collas, M., 2010. Effects of temperature and population density on von Bertalanffy growth parameters in Atlantic herring: a macro ecological analysis. Marine Ecology Progress Series, 405, 1528.

Brunel, T., Ernande, B., Mollet, F.M., Rijnsdorp, A.D. 2013. Coupling non-linear mixed statistical models and dynamic energy allocation models to determine the onset of maturation and related energy allocation parameters from somatic growth data. Oecologia, in press.

Conover, D.O., Duffy, T.A., Hice, L.A., 2009. The covariance between genetic and environmental influences across ecological gradients - reassessing the evolutionary significance of countergradient and cogradient Variation. The Year in Evolutionary Biology Ann. N. Y., 100-129.

Conover, D.O., Present, T.M.C., 1990. Countergradient variation in growth rate - compensation for length of the growing season among Atlantic silversides from different latitudes. Oecologia 83, 316-324.

Conover, D.O. Schultz, E.T., 1995 Phenotypic similarity and the evolutionary significance of countergradient variation. Trends in Ecology and Evolution 10, 248-252. (doi:10.1016/S0169-5347(00)89081-3)

Cuveliers, E., Larmuseau, M., Hellemans, B., Verherstraeten, S., Volckaert, F., Maes, G., 2012. Multi-marker estimate of genetic connectivity of sole (Solea solea) in the North-East Atlantic Ocean. Marine Biology 159, 1239-1253. doi: 10.1007/s00227-012-1905-x

Deniel, C., 1981.

, pleuronectiformes) en Baie de Douarnenez: reproduction, croissance et migration des Bothidae, Scophthalmidae, Pleuronectidae et Soleidae. PhD thesis,

Dhillon, R.S., Fox, M.G., 2004. Growth-independent effects of temperature on age and size at maturity in Japanese medaka (Oryzias latipes). Copeia 2004, 37-45.

Engelhard, G.H., Heino, M., 2004. Maturity changes in Norwegian spring spawning herring before, during, and after a major population collapse. Fisheries Research 66, 299-310.

643 Ernande B., Dieckmann, U., Heino, M. 2004. Adaptive changes in harvested populations: plasticity and 644 evolution of age and size at maturation. Proceedings of the Royal Society B Biological Sciences 271 , $415-423$. 
646 1 2647

Exadactylos, A., Geffen, A.J., Panagiotaki, P., Thorpe, J.P., 2003. Population structure of Dover sole Solea solea: RAPD and allozyme data indicate divergence in European stocks. Marine Ecology Progress Series 246, 253-264.

Fincham, J.I., Rijnsdorp, A.D., Engelhard, G.H., 2013. Shifts in the timing of spawning in sole linked to warming sea temperatures. Journal of Sea Research 75, 69-76. doi:10.1016/j.seares.2012.07.004

Fonds, M., Cronie, R., Vethaak, A.D., Van Der Puyl, P., 1992. Metabolism, food consumption and growth of plaice (Pleuronectes platessa) and flounder (Platichthys flesus) in relation to fish size and temperature. Netherlands Journal of Sea Research 29, 127-143.

Fox, C.J., O'Brien, C.M., Dickey-Collas, M., Nash, R.D.M., 2000. Patterns in the spawning of cod (Gadus morhua L.), sole (Solea solea L.) and plaice (Pleuronectes platessa L.) in the Irish Sea as determined by generalized additive modelling. Fisheries Oceanography 9, 33-49.

Gardner, J.L., Heinsohn, R., Joseph, L., 2009. Shifting latitudinal clines in avian body size correlate with global warming in Australian passerines. Proceedings of the Royal Society B Biological Sciences 276, 38453852.

Grift, R.E., Rijnsdorp, A.D., Barot, S., Heino, M., Dieckmann, U., 2003. Fisheries-induced trends in reaction norms for maturation in North Sea plaice. Marine Ecology Progress Series 257, 247-257.

Grift, R.E., Heino, M., Rijnsdorp, A.D., Kraak, S.B.M., Dieckmann, U., 2007. Three-dimensional maturation reaction norms for North Sea plaice. Marine Ecology Progress Series 334, 213-224.

Heino, M., Dieckmann, U., Godo, O.R. 2002. Measuring probabilistic reaction norms for age and size at maturation. Evolution 56, 669-678.

Heino, M., Godø, O.R., 2002. Fisheries-induced selection pressures in the context of sustainable fisheries. Bulletin of Marine Science 70, 639-656.

Horwood, J., 1993. The Bristol Channel sole (Solea solea (L.)) - a fisheries case-study. Advances in Marine Biology 29, 215-367.

Horwood, J.W., Millner, R.S., 1998. Cold induced abnormal catches of sole. Journal of the Marine Biological Association of the United Kingdom 78, 345-347.

Huret, M., Sourisseau, M., Petitgas, P., Struski, C., Léger, F., Lazure, P., 2013. A multi-decadal hindcast of a physical-biogeochemical model and derived oceanographic indices in the Bay of Biscay. Journal of Marine Systems. dx.doi.org/10.1016/j.jmarsys.2012.02.009. 
ICES, 2010. Report of the ICES Advisory Committee 2010. ICES Advice, 2010. Book 6, 309 pp.

Jørgensen, C., Enberg, K., Dunlop, E. S., Arlinghaus, R., Boukal, D.S., Brander, K., Ernande, B., Gårdmark, A., Johnston, F., Matsumura, S., Pardoe, H., Raab, K., Silva, A., Vainikka, A., Dieckmann, U., Heino, M., Rijnsdorp, A.D., 2007. Managing evolving fish stocks. Science 318, 1247-1248.

Jørgensen, C., Holt, R.E., 2013. Natural mortality: its ecology, how it shapes fish life histories, and why it may be increased by fishing. Journal of Sea Research 75, 8-18.

Jørgensen, T., 1990. Long-term changes in age at sexual maturity of Northeast Arctic cod (Gadus morhua L.). Journal du Conseil International pour l'Exploration de la Mer 46, 235-248.

Kuparinen, A., Cano, J.M., Loehr, J., Herczeg, G., Gonda, A., Merilä, J., 2011. Fish age at maturation is influenced by temperature independently of growth. Oecologia 167, 435-443.

Kurita, Y., Meier, S., Kjesbu, O.S., 2003. Oocyte growth and fecundity regulation by atresia of Atlantic herring (Clupea harengus) in relation to body condition throughout the maturation cycle. Journal of Sea Research 49, 203-219.

Laugen, A.T., Laurila, A., Räsänen, K., Merilä, J., 2003. Latitudinal countergradient variation in the common frog (Rana temporaria) development rates - evidence for local adaptation. Journal of Evolutionary Biology 16, 996-1005.

Laugen, A.T., Laurila, A., Jonsson, K., Soderman, F., Merilä, J., 2005. Do common frogs (Rana temporaria) follow Bergmann's rule? Evolutionary Ecology Research 7, 717-731.

Law, R., Grey, D.R., 1989. Evolution of yields from populations with age-specific cropping. Evolutionary Ecology 3, 343-359.

Lester, N.P., Shuter, B.J., Abrams, P.A., 2004. Interpreting the von Bertalanffy model of somatic growth in fishes: the cost of reproduction. Proceedings of the Royal Society of London Series B Biological Sciences 271, 1625-1631.

Lindgren, B., Laurila, A. 2005. Proximate causes of adaptive growth rates: growth efficiency variation among latitudinal populations of Rana temporaria. Journal of Evolutionary Biology 18, 820-828.

Lindgren, B., Laurila, A. 2010. Are high-latitude individuals superior competitors? A test with Rana temporaria tadpoles. Evolutionary Ecology 24, 115-131.

702 Lynch, M., Walsh, B. 1998. Genetics and Analysis of Quantitative Traits. Sinauer Associates. 
Litzgus, J.D., Durant, S.E., Mousseau, T.A., 2004. Clinal variation in body and cell size in a widely distributed vertebrate ectotherm. Oecologia 140, 551-558.

Lonsdale, D.J., Levinton, J.S., 2011. Latitudinal differentiation in copepod growth: an adaptation to temperature. Ecology 66, 1397-1407.

Marcil, J., Swain, D.P., Hutchings, J.A., 2006. Countergradient variation in body shape between two populations of Atlantic cod (Gadus morhua). Proceedings of the Royal Society B Biological Sciences $273,217-223$.

Millner, R.S., Walsh, S.J., Diaz de Asarloa, J.M., 2005. Atlantic flatfish fisheries. In: Gibson, R.N. (Ed.), Flatfishes: Biology and exploitation. Blackwell Science Ltd, Oxford, UK, pp. 240-271

Mollet, F.M., Ernande, B., Brunel, T., Rijnsdorp, A.D., 2010. Multiple growth-correlated life history traits estimated simultaneously in individuals. Oikos 119, 10-26.

Mollet, F.M., Kraak, S.B.M., Rijnsdorp, A.D., 2007. Fisheries-induced evolutionary changes in maturation reaction norms in North Sea sole Solea solea. Marine Ecology Progress Series 351, 189-199.

Mousseau, T.A., 1997. Ectotherms follow the converse to Bergmann's rule. Evolution 51, 630-632.

Neuheimer, A.B., Grønkjaer, P., 2012. Climate effects on size-at-age: growth in warming waters compensates for earlier maturity in an exploited marine fish. Global Change Biology 18,1812-1822.

O'Brien, L., 1999. Factors influencing the rate of sexual maturity and the effect on spawning stock for Georges Bank and Gulf of Maine Atlantic cod Gadus morhua stocks. Journal of Northwest Atlantic Fisheries Science 25, 179-203.

Partridge, L., Coyne, J.A., 1997. Bergmann's rule in ectotherms: is it adaptive? Evolution 51, 632-635.

Pinheiro, J.C., Bates, D.M., 2004. Mixed-Effects Models in S and S-PLUS. Statistics and Computing. Springer, New York, USA, $528 \mathrm{pp}$.

Pinheiro, J., Bates, D., DebRoy, S., Sarkar, D., and the R Development Core Team. 2011. nlme: Linear and Nonlinear Mixed Effect Models. R package version 3.1-102

R Development Core Team. 2011. R: A language and environment for statistical computing. R Foundation for Statistical Computing, Vienna, Austria.

Rijnsdorp, A.D., 1990. The mechanism of energy allocation over reproduction and somatic growth in female North Sea plaice, Pleuronectes platessa L. Netherlands Journal of Sea Research 25, $279-289$. 
Rijnsdorp, A.D., Van Beek, F.A., Flatman, S., Millner, R., Giret, M., De Clerck, R., 1992. Recruitment of sole stocks, Solea solea (L.), in the northeast Atlantic. Netherlands Journal of Sea Research 29, 173-192.

Rijnsdorp, A.D., Vingerhoed, B., 1994. The ecological significance of geographical and seasonal differences in egg size in sole Solea solea (L.). Netherlands Journal of Sea Research 32, 255-270.

Rijnsdorp, A.D., Witthames, P., 2005. Ecology of reproduction. In Gibson, R.N. (Ed.), Flatfishes: Biology and Exploitation. Blackwell Science, Oxford, UK, pp. 68-93.

Rijnsdorp, A.D., Poos, J.J., Quirijns, F.J., HilleRisLambers, R., de Wilde, J.W., Den Heijer, W.M., 2008. The arms race between fishers. Journal of Sea Research 60, 126-138

Roff, D.A., 1992. The evolution of life histories. New York: Chapman \& Hall.

Schultz, E.T., Reynolds, K.E., Conover, D.O., 1996. Countergradient variation in growth among newly hatched Fundulus heteroclitus: geographic differences revealed by common-environment experiments. Functional Ecology 10, 366-374.

Skelly, D.K., 2004. Microgeographic countergradient variation in the Wood Frog, Rana sylvatica. Evolution 58, $160-165$

Stearns, S.C., 1992. The evolution of life histories. New York: Oxford University Press.

Søiland, H., Skogen, M.D., 2000. Validation of a three-dimensional biophysical model using nutrient observations in the North Sea. ICES Journal of Marine Science 57, 816-823.

Toresen, R., 1990. Long term changes in growth of Norwegian spring spawning herring. Journal du Conseil International pour l'Exploration de la Mer 47, 48-56.

Trussell, G.C., 2000. Phenotypic clines, plasticity, and morphological trade-offs in an intertidal snail. Evolution 54, 151-166.

Trussell, G.C., 2002. Evidence of countergradient variation in the growth of an intertidal snail in response to water velocity. Marine Ecology Progress Series 243, 123-131.

Uusi-Heikkilä, S., Kuparinen, A., Wolter, C., Meinelt, T., O’Toole, A.C.O., Arlinghaus, R., 2011. Experimental assessment of the probabilistic maturation reaction norm: condition matters. Proceedings of the Royal Society B Biological Sciences 278, 709-17.

Vainikka, A., Mollet, F., Casini, M., Gårdmark, A., 2009: Spatial variation in growth, condition and maturation reaction norms of the Baltic herring (Clupea harengus membras). Marine Ecology Progress Series 383, 285-294. 
760 Van Voorhies, W.A., 1997. On the adaptive nature of Bergmann size clines: a reply to Mousseau, Partridge and

1 Coyne. Evolution 51, 635-640.

West, G.B., Brown, J.H., Enquist, B.J., 2001. A general model for ontogenetic growth. Nature 413, 628-631.

Witthames, P.R., Walker, M.G., Dinis, M.T., Whiting, C.L., 1995. The geographical variation in the potential annual fecundity of Dover sole Solea solea (L) from European shelf waters during 1991. Netherlands Journal of Sea Research 34, 45-58.

Woodhead, P.J.M., 1964. The death of North Sea fish during the winter of 1962/63 particularly with reference to the sole, Solea vulgaris. Helgoländer Wissenschaftliche Meeresuntersuchungen 10, 283-300. 
470 Table 1: Sample numbers per area and age group, number of data points (individuals) used in growth 5771 (\#growth) and maturation (\#mature) analysis and the proportion of matures (\%mature) at age 7772 (referring to the age at spawning). The differences between the growth and maturity data selection

\begin{tabular}{|c|c|c|c|c|c|c|c|c|c|}
\hline area & $\begin{array}{l}\text { Count (\#) or } \\
\text { percentage }(\%)\end{array}$ & age1 & age2 & age3 & age4 & age5 & age6 & age $7+$ & total \\
\hline \multirow{3}{*}{$8 \mathbf{a}$} & \#growth & 32 & 386 & 602 & 673 & 589 & 410 & 770 & 3462 \\
\hline & \#mature & 4 & 99 & 107 & 159 & 166 & 134 & 270 & 939 \\
\hline & $\%$ mature & 0.00 & 0.01 & 0.15 & 0.63 & 0.80 & 0.84 & 0.92 & 0.65 \\
\hline \multirow{3}{*}{$7 e$} & \#growth & 34 & 167 & 567 & 660 & 476 & 294 & 636 & 2834 \\
\hline & \#mature & 0 & 22 & 283 & 328 & 151 & 155 & 288 & 1227 \\
\hline & $\%$ mature & NA & 0.14 & 0.71 & 0.94 & 0.99 & 0.99 & 1.00 & 0.90 \\
\hline \multirow{3}{*}{$7 d$} & \#growth & 565 & 2390 & 2668 & 2365 & 1664 & 910 & 2103 & 12670 \\
\hline & \#mature & 4 & 161 & 844 & 808 & 562 & 354 & 877 & 3610 \\
\hline & $\%$ mature & 0.75 & 0.13 & 0.60 & 0.82 & 0.81 & 0.84 & 0.92 & 0.76 \\
\hline \multirow{3}{*}{$7 \mathrm{fg}$} & \#growth & 510 & 776 & 335 & 316 & 395 & 214 & 511 & 3116 \\
\hline & \#mature & 0 & 1 & 15 & 58 & 87 & 87 & 192 & 440 \\
\hline & $\%$ mature & NA & 0.00 & 0.53 & 0.93 & 0.98 & 0.99 & 1.00 & 0.97 \\
\hline \multirow{3}{*}{$4 c$} & \#growth & 789 & 1968 & 4299 & 4696 & 3733 & 1935 & 3940 & 21458 \\
\hline & \#mature & 10 & 179 & 1275 & 1411 & 1085 & 615 & 1071 & 5646 \\
\hline & $\%$ mature & 0.00 & 0.38 & 0.93 & 0.96 & 0.94 & 0.96 & 0.92 & 0.92 \\
\hline \multirow{3}{*}{$4 \mathrm{bW}$} & \#growth & 1 & 114 & 261 & 195 & 156 & 141 & 194 & 1062 \\
\hline & \#mature & 0 & 19 & 105 & 95 & 83 & 66 & 87 & 455 \\
\hline & $\%$ mature & NA & 0.26 & 0.80 & 0.93 & 1.00 & 1.00 & 1.00 & 0.91 \\
\hline \multirow{3}{*}{$7 \mathbf{a}$} & \#growth & 274 & 629 & 523 & 540 & 367 & 192 & 397 & 2928 \\
\hline & \#mature & 0 & 0 & 19 & 48 & 56 & 23 & 98 & 244 \\
\hline & $\%$ mature & NA & NA & 1.00 & 0.96 & 1.00 & 1.00 & 1.00 & 0.99 \\
\hline \multirow{3}{*}{$4 b E$} & \#growth & 269 & 975 & 2064 & 2291 & 1349 & 803 & 1048 & 8850 \\
\hline & \#mature & 0 & 72 & 695 & 922 & 560 & 341 & 471 & 3061 \\
\hline & $\%$ mature & NA & 0.50 & 0.95 & 0.99 & 1.00 & 1.00 & 1.00 & 0.97 \\
\hline \multirow{3}{*}{ total } & \#growth & 2474 & 7405 & 11319 & 11736 & 8729 & 4899 & 9599 & 56380 \\
\hline & \#mature & 2474 & 7405 & 11319 & 11736 & 8729 & 4899 & 3354 & 15622 \\
\hline & $\%$ mature & 0.17 & 0.24 & 0.80 & 0.92 & 0.92 & 0.94 & 0.95 & 0.88 \\
\hline
\end{tabular}


778 Table 2: Environmental conditions and estimated growth parameters and derived quantities (see text) 779 for each stock based on random effects estimated in the random area effect model (eq. 4). Mean 780 latitude and temperature as described in text; $\mathrm{CV}$ recruitment: coefficient of variation of the number 781 of recruits over the last 25 - 50 years (periods of available data differ between areas) from Rijnsdorp 782 \& Witthames (2005); Mean F: mean fishing mortality, fishing mortality data from ICES Fish Stock 783 Assessment Summary Database (2010); $a$ : size-specific energy acquisition rate, $c$ : size-specific 784 reproductive investment rate; $w_{\text {mat }}:$ weight at maturation; $t_{\text {mat }}:$ age at maturation; $L_{\mathrm{P} 50}$ : PMRN midpoint 785 at age $3 ; W_{\mathrm{P} 50}$ : weight corresponding to PMRN midpoint at age $3 ; L_{\infty}$ : asymptotic length; $W_{\infty}$ : 786 asymptotic weight; se(x): standard error of estimate $x$ obtained by bootstrapping.

\begin{tabular}{|c|c|c|c|c|c|c|c|c|}
\hline Stock & $8 a$ & $7 e$ & $7 d$ & $7 \mathrm{fg}$ & $4 c$ & $4 \mathrm{bW}$ & $7 a$ & $4 b E$ \\
\hline Latitude $\left[^{\circ} \mathbf{N}\right]$ & 47 & 49.7 & 50.5 & 51.4 & 51.7 & 53.5 & 54 & 54.5 \\
\hline Temperature $\left[{ }^{\circ} \mathrm{C}\right]$ & 13.6 & 11.8 & 11.8 & 11.1 & 11.3 & 9.5 & 10.6 & 9.8 \\
\hline Day of peak spawning & 58 & 91 & 111 & 86 & 118 & 151 & 136 & 148 \\
\hline$C V$ Recruitment & $19 \%$ & $36 \%$ & $38 \%$ & $43 \%$ & $90 \%^{1}$ & $90 \%^{1}$ & $75 \%$ & $90 \%{ }^{1}$ \\
\hline Mean $F^{2}$ & 0.515 & 0.339 & 0.424 & 0.482 & 0.541 & 0.541 & 0.483 & 0.541 \\
\hline$a\left[\mathrm{~g}^{1 / 4} \mathrm{yr}^{-1}\right]$ & 4.55 & 5.10 & 5.17 & 5.61 & 5.26 & 4.59 & 5.16 & 5.89 \\
\hline $\operatorname{se}(a)\left[\mathrm{g}^{1 / 4} \mathrm{yr}^{-1}\right]$ & 0.09 & 0.40 & 0.21 & 0.14 & 0.07 & 0.23 & 0.09 & 0.07 \\
\hline$c\left[\mathbf{y r}^{-1}\right]$ & 0.678 & 0.870 & 0.904 & 1.000 & 0.904 & 0.776 & 0.942 & 1.042 \\
\hline $\operatorname{se}(c)\left[\mathrm{yr}^{-1}\right]$ & 0.025 & 0.083 & 0.052 & 0.038 & 0.017 & 0.053 & 0.024 & 0.018 \\
\hline$w_{\text {mat }}[g]$ & 117 & 129 & 119 & 68 & 49 & 118 & 81 & 67 \\
\hline$s e\left(w_{\text {mat }}\right)[g]$ & 6.90 & 38.47 & 12.21 & 4.37 & 4.42 & 19.20 & 4.00 & 3.19 \\
\hline$t_{\text {mat }}[\mathrm{yr}]$ & 2.54 & 2.34 & 2.25 & 1.76 & 1.72 & 2.53 & 2.02 & 1.67 \\
\hline$s e\left(t_{\mathrm{mat}}\right)[\mathrm{yr}]$ & 0.09 & 0.38 & 0.15 & 0.08 & 0.07 & 0.23 & 0.06 & 0.04 \\
\hline$L_{\mathrm{P} 50}[\mathrm{~cm}]$ & 27.8 & 24.3 & 25.3 & 26.3 & 24.1 & 25.2 & 23.2 & 22.9 \\
\hline$W_{\text {P50 }}[\mathrm{g}]$ & 185 & 146 & 170 & 178 & 133 & 130 & 172 & 97 \\
\hline$L_{\infty}[\mathbf{c m}]$ & 57.56 & 48.26 & 47.21 & 46.15 & 49.62 & 50.50 & 44.89 & 48.00 \\
\hline $\operatorname{se}\left(L_{\infty}\right)[\mathrm{cm}]$ & 1.19 & 1.06 & 0.82 & 0.86 & 0.36 & 1.15 & 0.56 & 0.31 \\
\hline$W_{\infty}[g]$ & 2031 & 1175 & 1071 & 993 & 1142 & 1222 & 899 & 1023 \\
\hline $\operatorname{se}\left(W_{\infty}\right)[g]$ & 130 & 81 & 55 & 60 & 26 & 87 & 34 & 21 \\
\hline
\end{tabular}

$787 \quad{ }^{1}$ Recruitment variability for total North Sea stock (4c, $4 \mathrm{bW}, 4 \mathrm{bE}$ combined).

$788{ }^{2}$ Mean F for the years 1984-2007, averaged over ages 3-6 (area 8a), 3-7 (7e), 3-8 (7d), 4-8 (7fg), 4-7 (Irish 789 Sea), and 2-6 (4c, 4bW, 4bE). 
790 Table 3: Comparison of the performance of the three nonlinear mixed effect models. Random 1791 area effect model: model with constant fixed effects and area random effects acting on the 4792 three parameters $\left(a, c, w_{\text {mat }}\right)$ with a symmetric covariance matrix; Latitude effect model: 793 model with fixed effects depending linearly on area average latitude and area random effects 794 on parameter $a$ and $w_{\text {mat }}$ with a symmetric covariance matrix; Temperature effect model: 795 model with fixed effects depending linearly on area average temperature and area random 
805 Table 4: Detailed effects of latitude or temperature on the three parameters of the growth 1

for each parameter together with the degrees of freedom (df), t-value and associated p-value 811 testing for its significance.

812 Parameter Estimate

\section{$813 \quad$ Latitude effect model}

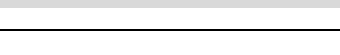

815

816

817

$a_{0, \text { Lat }_{2}}$

4.61

0.10

56367

46.37

$<0.0001$

$a_{1, \text { Lat }}$

0.15

0.20

$56367 \quad 7.68$

$<0.0001$

$c_{0, \text { Latz }}$

0.717

0.011

56367

66.19

$<0.0001$

$c_{1, \text { Lat }}$

0.045

0.002

56367

20.74

$<0.0001$

$w_{\text {mat }, 0, \text { Lat }}$

129

22.58

56367

5.71

$<0.0001$

$w_{\text {mat, } 1, \text { Lat }_{z}}$

$-9$

4.40

56367

$-2.14$

0.0327

\section{Temperature effect model}

821

822

823

$a_{0, \overline{T_{z}}}$

5.86

$a_{1, \overline{T_{z}}}$

$-0.28$

$c_{0, \bar{T}_{z}}$

1.076

0.09

56367

67.78

$<0.0001$

824

$c_{1, \bar{T}_{z}}$

$-0.081$

0.04

56367

$-6.62$

$<0.0001$

$825 w_{\text {mat }, 0, \bar{T}_{z}}$

$51 \quad 15.94$

56367

$w_{\text {mat }, 1, \overline{T_{z}}}$

17

7.92

56367

3.20

0.0014

827 
828 Table 5: Randomization tests for pairwise differences in PMRN between areas. p-values give the 1829 likelihood that the difference between two stocks arises by chance only, based on $10^{4}$ repetitions of 830 the PMRN midpoints calculation after randomizing subpopulations. Differences in PMRN midpoints 5831 between subpopulations for which this likelihood is higher than $5 \%$ are given in bold.

\begin{tabular}{l|llllllll}
$\mathbf{8 a}$ & & & & & & & \\
$\mathbf{7 e}$ & 0.000 & & & & & & \\
$\mathbf{7 d}$ & 0.000 & 0.004 & & & & & \\
$\mathbf{7 f g}$ & 0.019 & 0.002 & 0.015 & & & & \\
$\mathbf{4 c}$ & 0.000 & $\mathbf{0 . 0 9 3}$ & 0.000 & 0.000 & & & \\
$\mathbf{4 b W}$ & 0.000 & 0.049 & $\mathbf{0 . 3 9 0}$ & 0.045 & 0.002 & & \\
$\mathbf{7 a}$ & 0.004 & $\mathbf{0 . 0 7 2}$ & 0.022 & 0.011 & $\mathbf{0 . 1 2 1}$ & 0.028 & $\mathbf{0 . 3 7 8}$ \\
$\mathbf{4 b E}$ & 0.000 & 0.000 & 0.000 & 0.000 & 0.000 & 0.000 & $\mathbf{4 b E}$ \\
\hline & $\mathbf{8 a}$ & $\mathbf{7 e}$ & $\mathbf{7 d}$ & $\mathbf{7 f g}$ & $\mathbf{4 c}$ & $\mathbf{4 b W}$ & $\mathbf{7 a}$
\end{tabular}


833 Figure 1: Possible latitudinal clines in phenotypic expression and their underlying genetic and 834 environmental causes (modified from Conover and Schultz, 1995; Conover et al., 2009). In this 835 example temperature decreases with latitude (see Fig. 3), and we use growth rate as an example of 836 phenotype. In ectotherms such as fish, lower temperature generally slows down physiological rates 837 (solid line), but the resulting phenotype (dashed line) also depend on the genetic influence (dotted 838 line) and the interaction between the environmental and the genetic processes along the gradient.

839 A: There is no genetic variation for growth between populations along the gradient, and the resulting 840 phenotypic variation is determined by the change in environmental conditions (phenotypic expression 841 - dashed line - coincides with environmental influence - solid line).

842 B: The genotypic influence on a trait along the gradient is positively correlated to environmental 843 influence on a trait along a gradient. For growth rate this will occur if there is selection for fast growth 844 in an environment that favours growth (e.g. high temperature) and vice versa. Morphological 845 characters have often been found to display CoGV (Conover et al., 2009)

846 C: The genotypic influence on a trait along the gradient opposes the environmental influence on a trait 847 along the gradient. For growth this will occur if there is strong selection for faster growth in 848 environments that tend to slow down growth (e.g. low temperature, restricted growth season, see e.g. 849 Laugen et al., 2003).

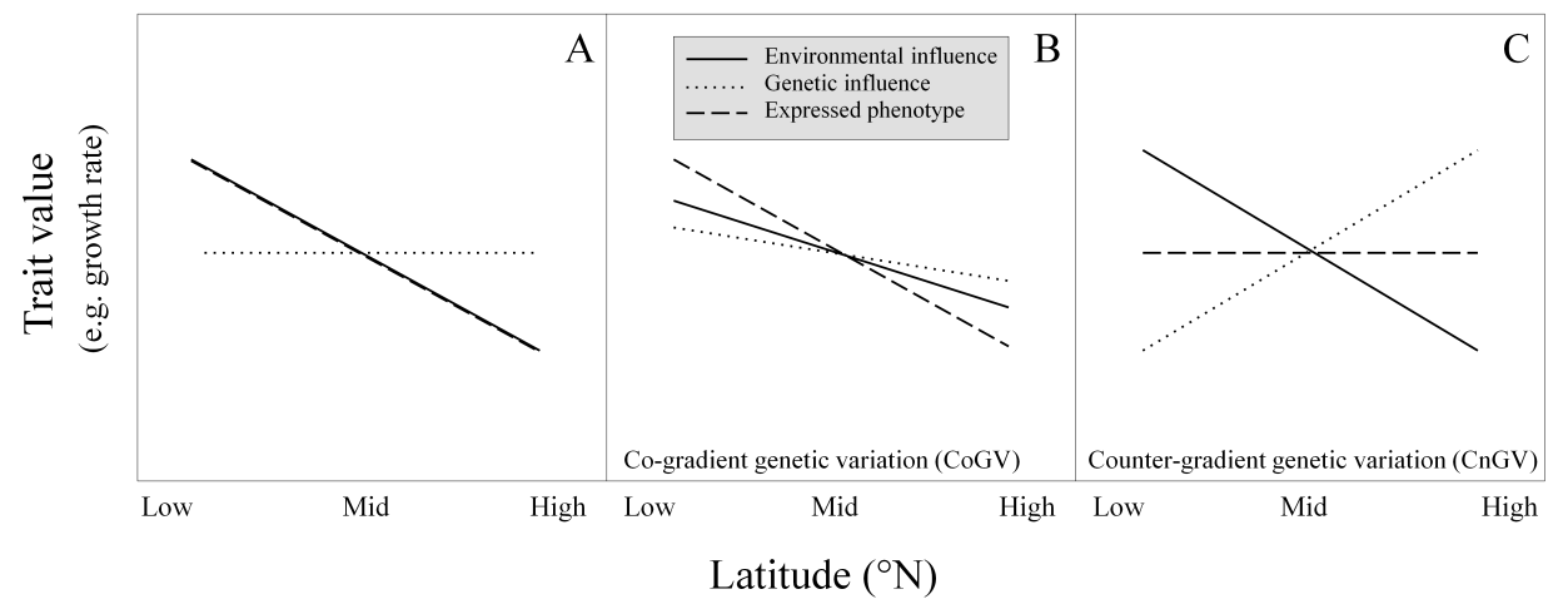


853 Figure 2: Geographic distribution of the study sole populations. Map showing the definition of eight

1 3855 4

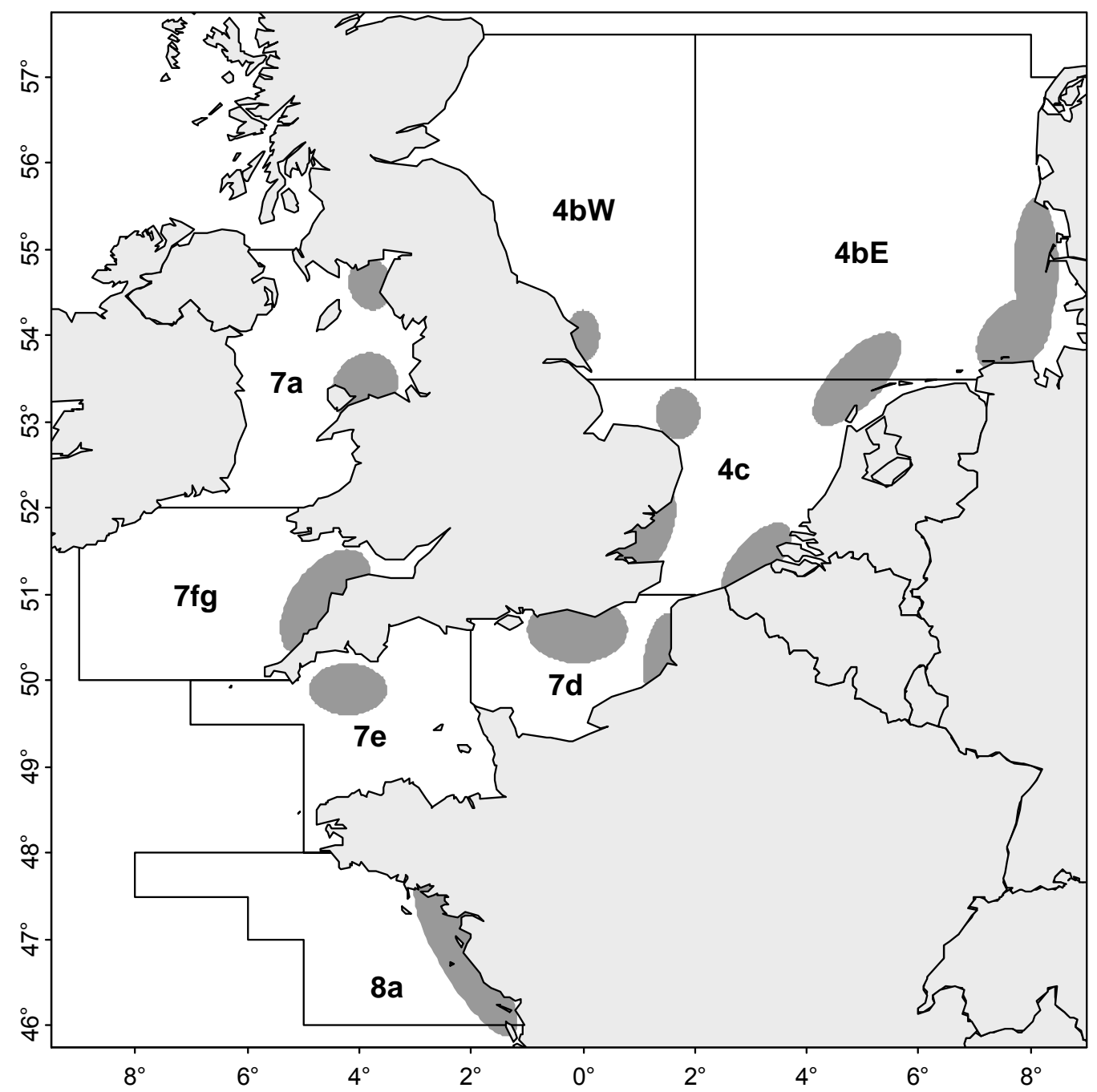


858 Figure 3: Latitudinal clines in sea bottom temperature and spawning timing of sole. Relationship

859 between latitude and bottom temperature (from a biophysical model: NORWECOM, IMR; and hydrodynamical model MARS3D, IFREMER, see text) for the different study populations (upper panel). Symbols indicate the annual mean, and bars the minimum and maximum temperatures throughout the year. Relationship of latitude with peak spawning day (filled circles) as suggested by literature for the different study populations of sole, and the spawning low (open circles) as estimated from the minimal condition in the seasonal cycle (see eq. 6 , predicted for a body length of $35 \mathrm{~cm}$, lower panel).

865 Days are Julian dates referring to the $1^{\text {st }}$ of January as start of the year. The dotted lines represent 866 linear regressions of the thereby approximated start and end of spawning weighted by the number of 867 observations in each stock.
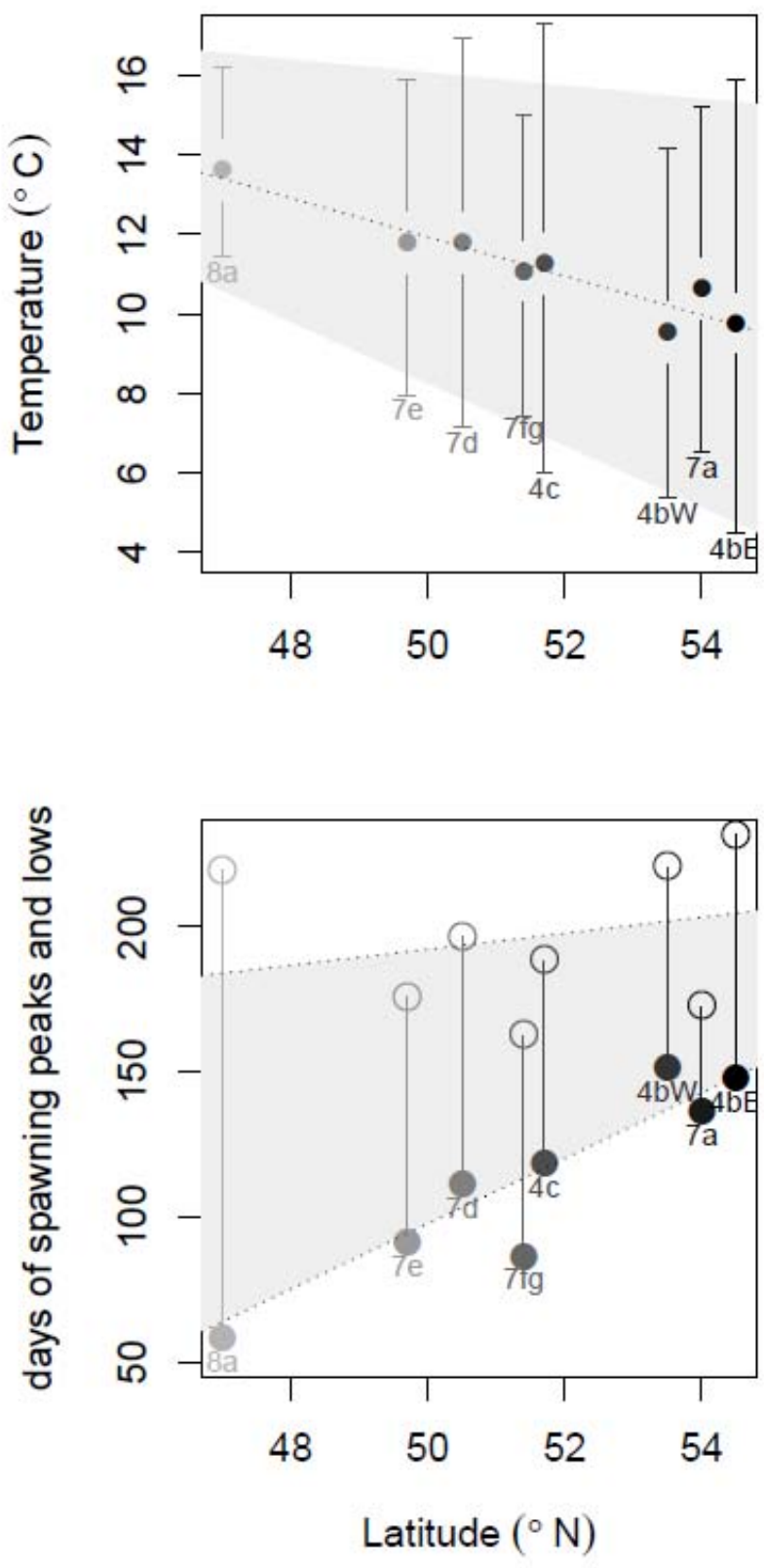
869 Figure 4: Latitudinal cline in growth curves. Age at weight data with means and $95 \%$ confidence

1 7873
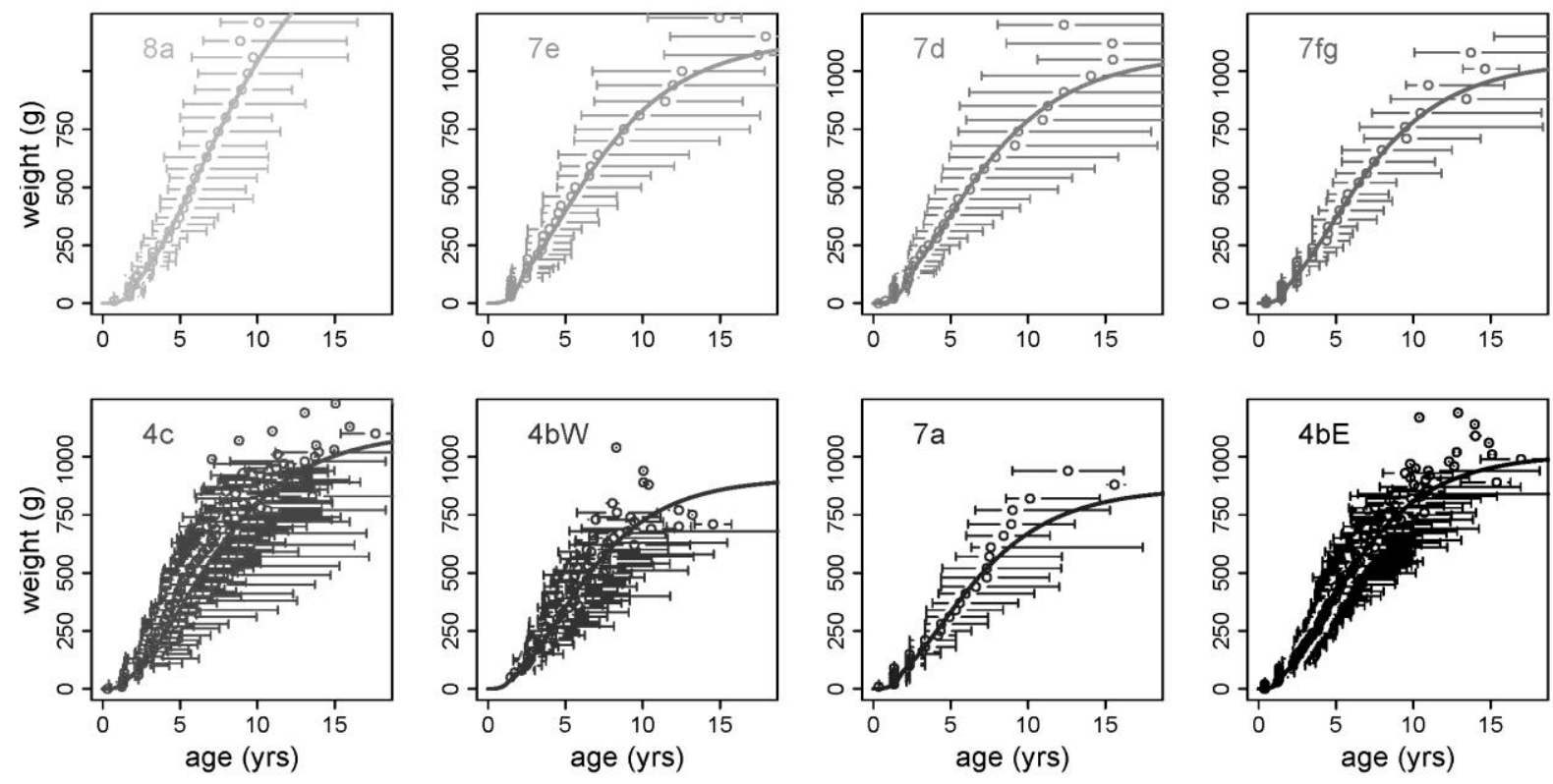
878 Figure 5: Latitudinal and temperature-related phenotypic clines in life-history parameters of the 879 879 energy allocation model. The three fitted energy allocation parameters, energy acquisition rate $a$, 880 reproductive investment rate $c$, onset of maturation $w_{\text {mat }}$ for each stock (see $\boldsymbol{\mu}\left(x_{z}\right)+\Delta \boldsymbol{\mu}_{z}$ in eq. 4) 881 and the underlying temperature effect on the fixed effects across stocks (dotted line, see $\boldsymbol{\mu}\left(x_{z}\right)$ in eq. 882 4) of the temperature effect model (upper panel) and the latitude effect model (lower panel, see 883 corresponding values in Table 4).
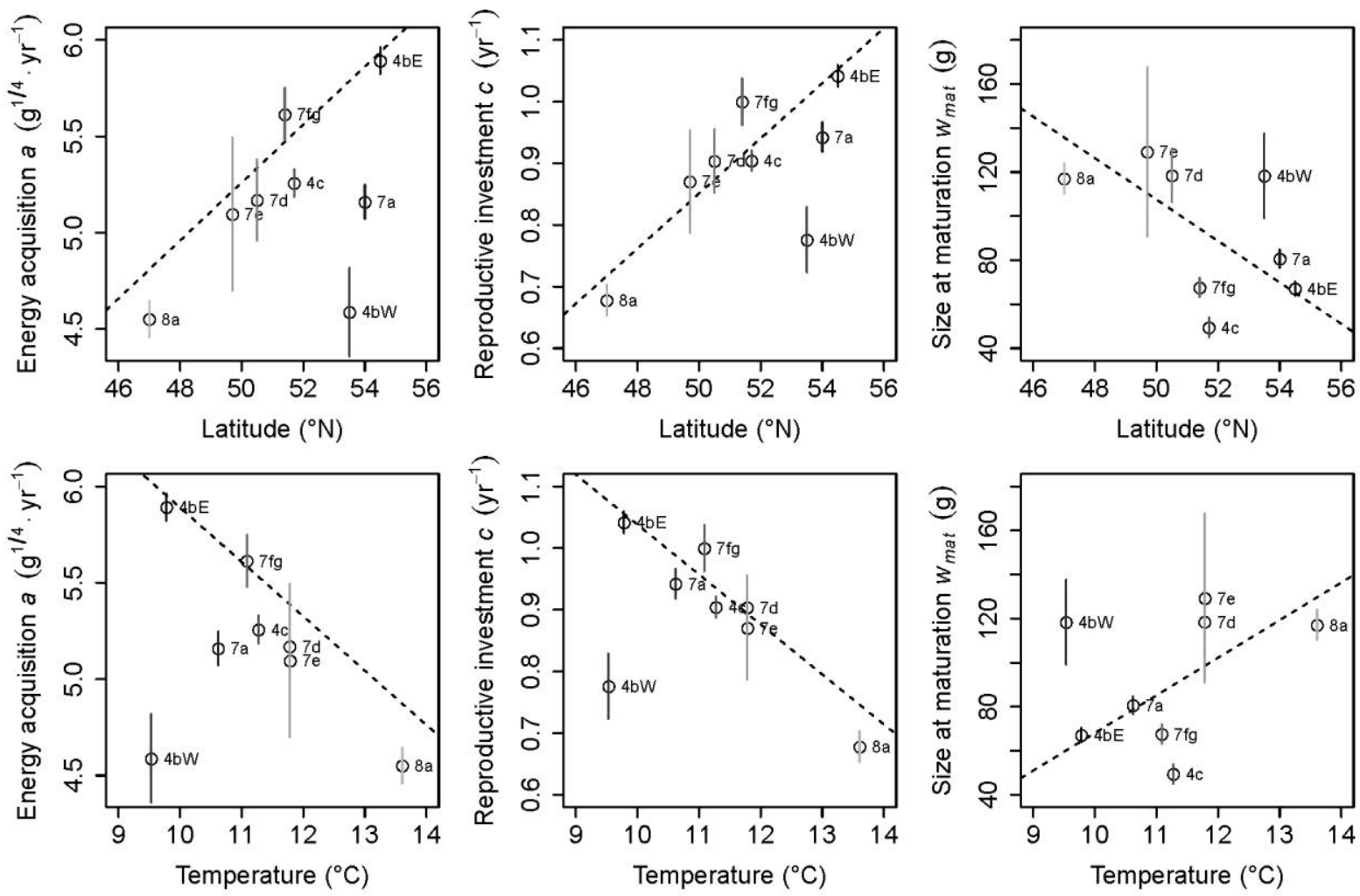
887 Figure 6: Temperature-related phenotypic clines in derived life-history traits. Age at maturation $t_{\text {mat }}$,

1
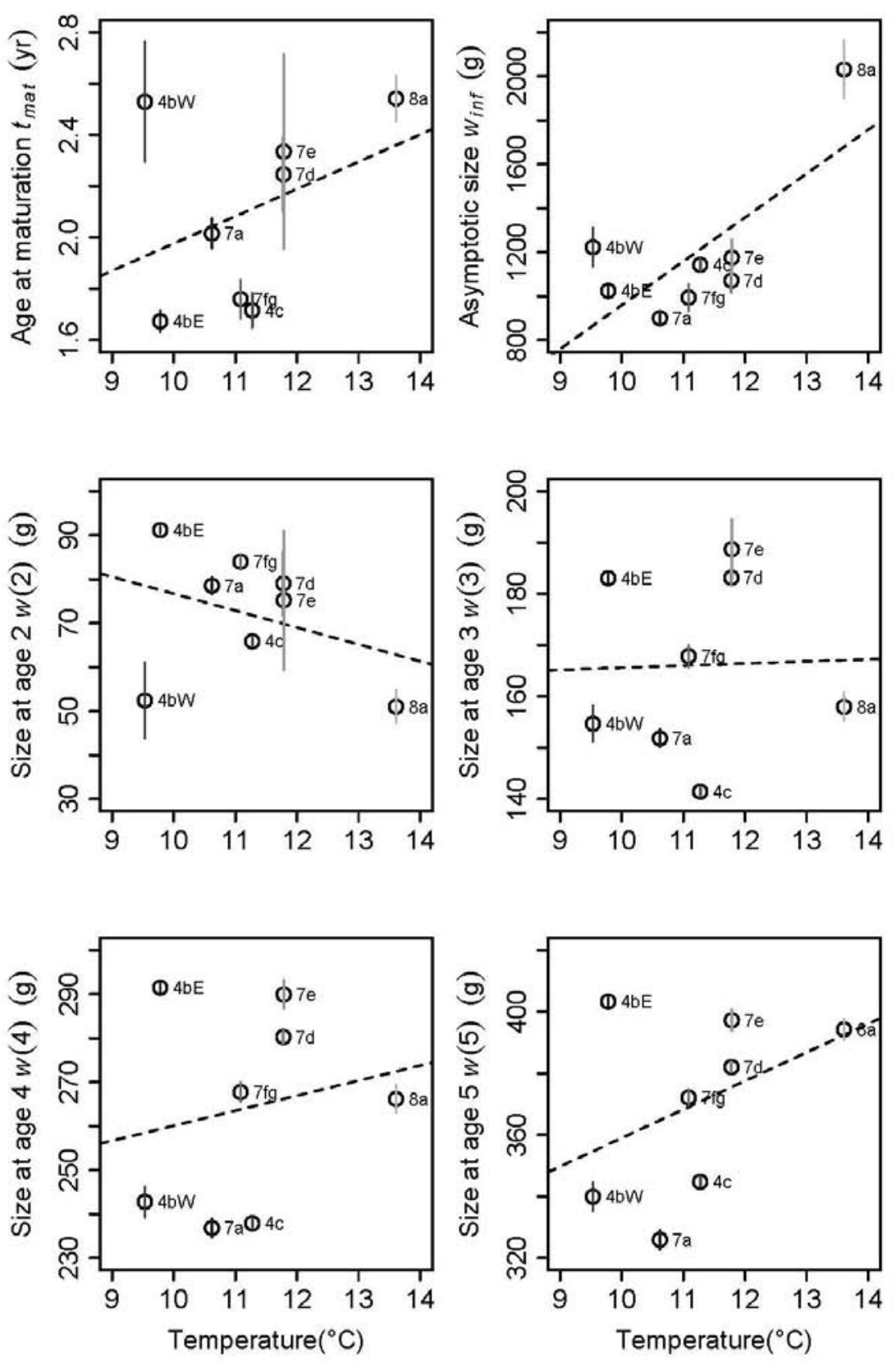
895 Figure 7: PMRNs in length $(\mathrm{cm})$ for the $50 \%$ probability of maturing as a function of age for the 8

1

2

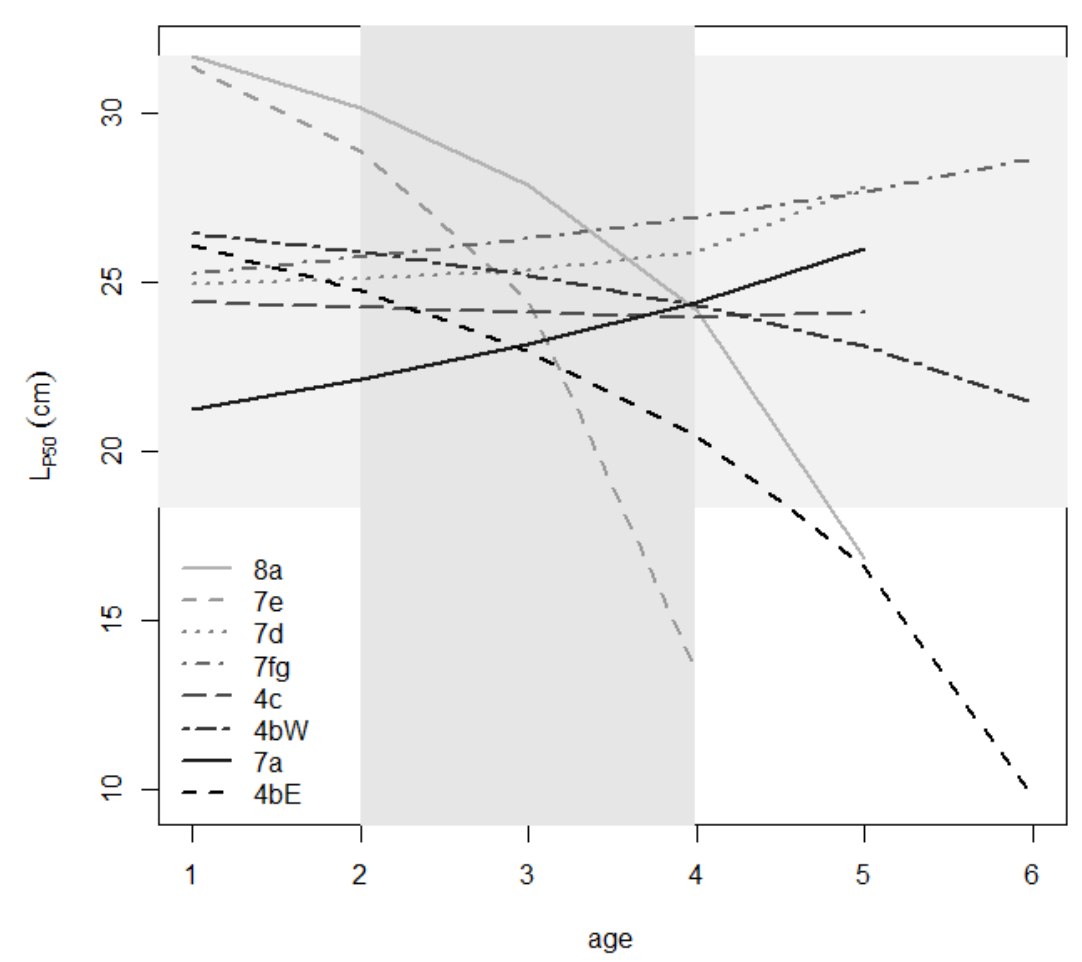


912 Figure 8: PMRN $L_{\mathrm{P} 50}$ midpoints at age 3, the age at which most individuals become mature, as a

2913 function of temperature (left panel) and latitude (right panel) with upper and lower 95\%-confidence

3
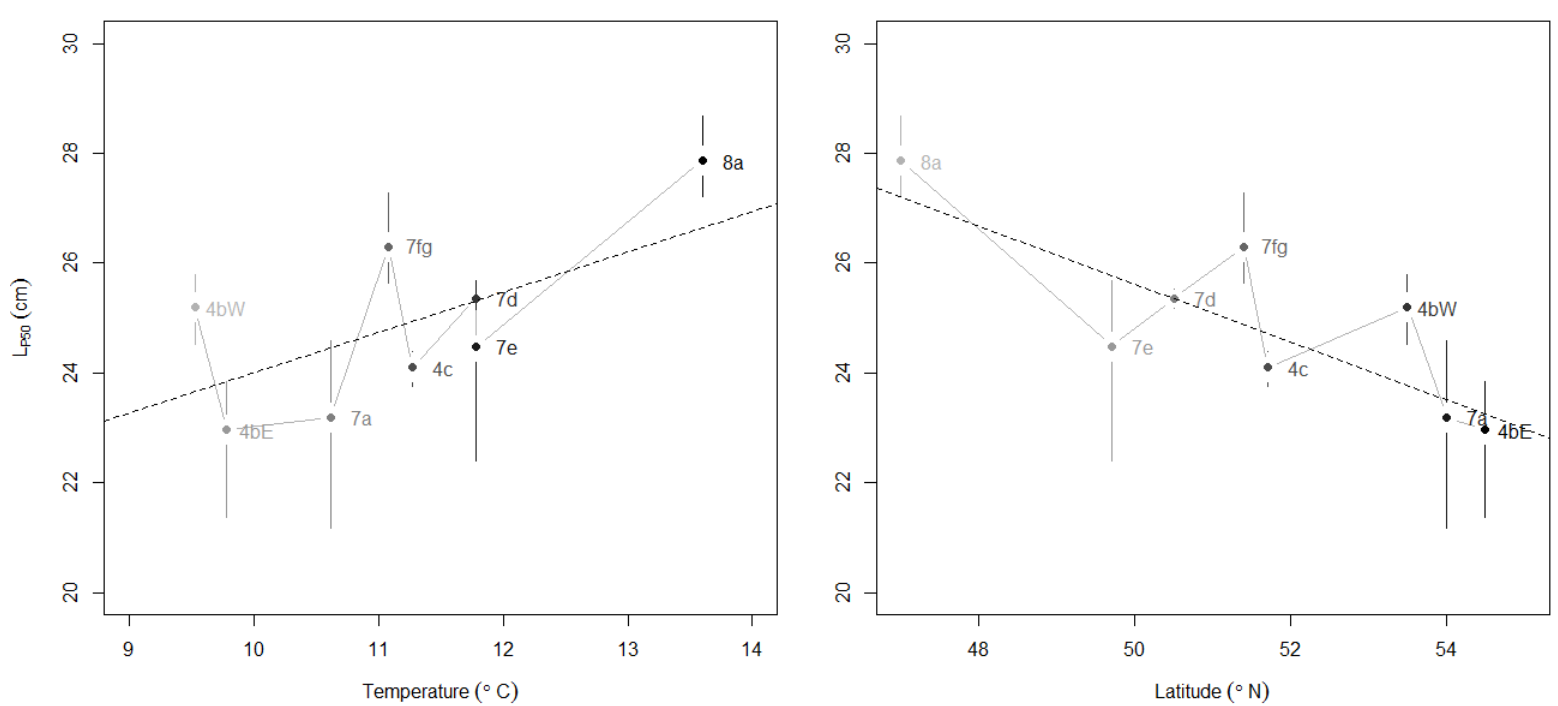